University of Massachusetts Amherst

ScholarWorks@UMass Amherst

Masters Theses 1911 - February 2014

1983

\title{
A role for serotonin in the hypothalamic-pituitary-adrenal response to insulin stress.
}

Rachel Yehuda

University of Massachusetts Amherst

Follow this and additional works at: https://scholarworks.umass.edu/theses

Yehuda, Rachel, "A role for serotonin in the hypothalamic-pituitary-adrenal response to insulin stress." (1983). Masters Theses 1911 - February 2014. 2284.

https://doi.org/10.7275/7ja0-hy89

This thesis is brought to you for free and open access by ScholarWorks@UMass Amherst. It has been accepted for inclusion in Masters Theses 1911 - February 2014 by an authorized administrator of ScholarWorks@UMass Amherst. For more information, please contact scholarworks@library.umass.edu. 


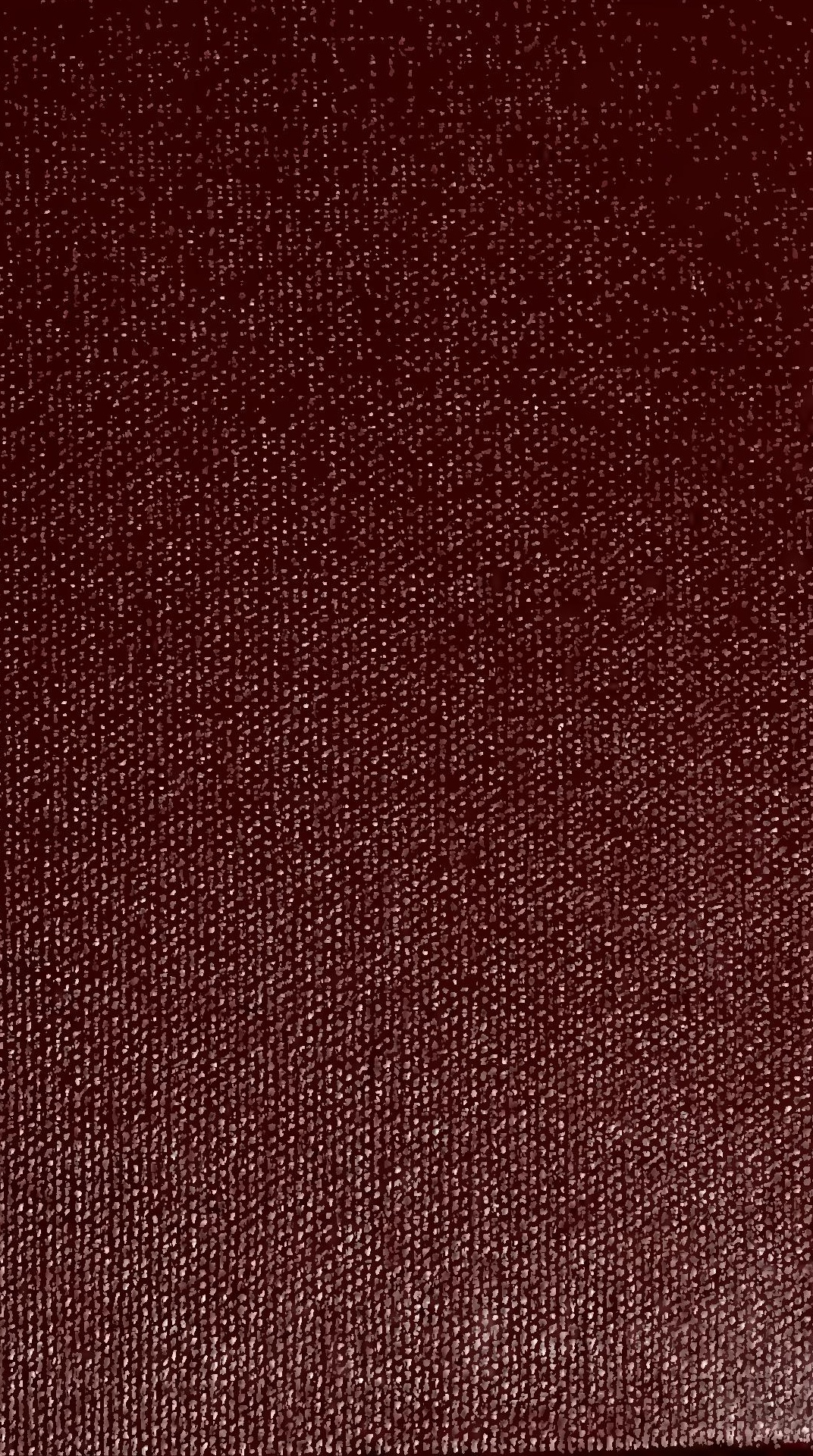




\section{A ROLE FOR SEROTONIN IN THE HYPOTHALAMIC-PITUITARY-ADRENAL RESPONSE TO INSULIN STRESS}

\section{A Thesis Presented}

By

RACHEL YEHUDA

Submitted to the Graduate School of the University of Massachusetts in partial fulfillment

of the requirements for the degree of

\section{MASTER OF SCIENCE}

$$
\text { May } 1983
$$

Department of Psychology 
A ROLE FOR SEROTONIN IN THE HYPOTHALAMIC-PITUITARY-ADRENAL

RESPONSE TO INSULIN STRESS

A Thesis Presented

By

RACHEL YEHUDA

Approved as to style and content by:

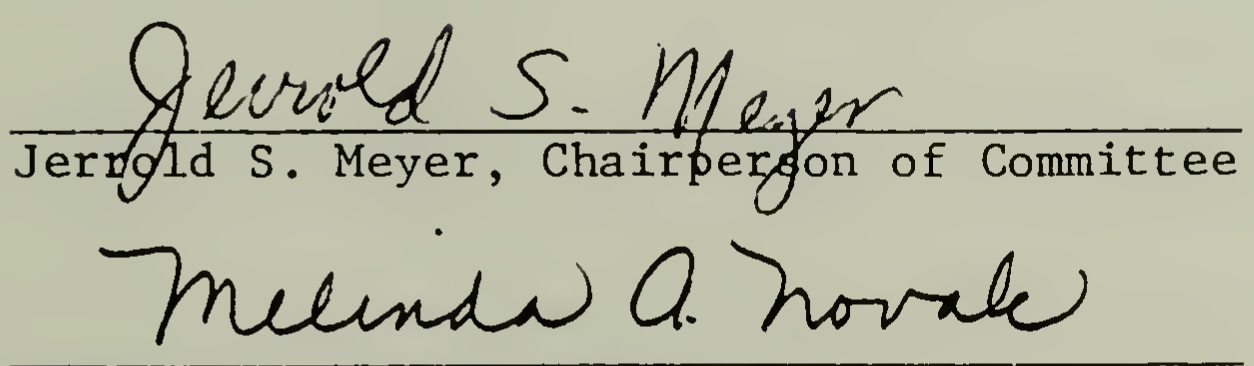

Melinda A. Novak, Member

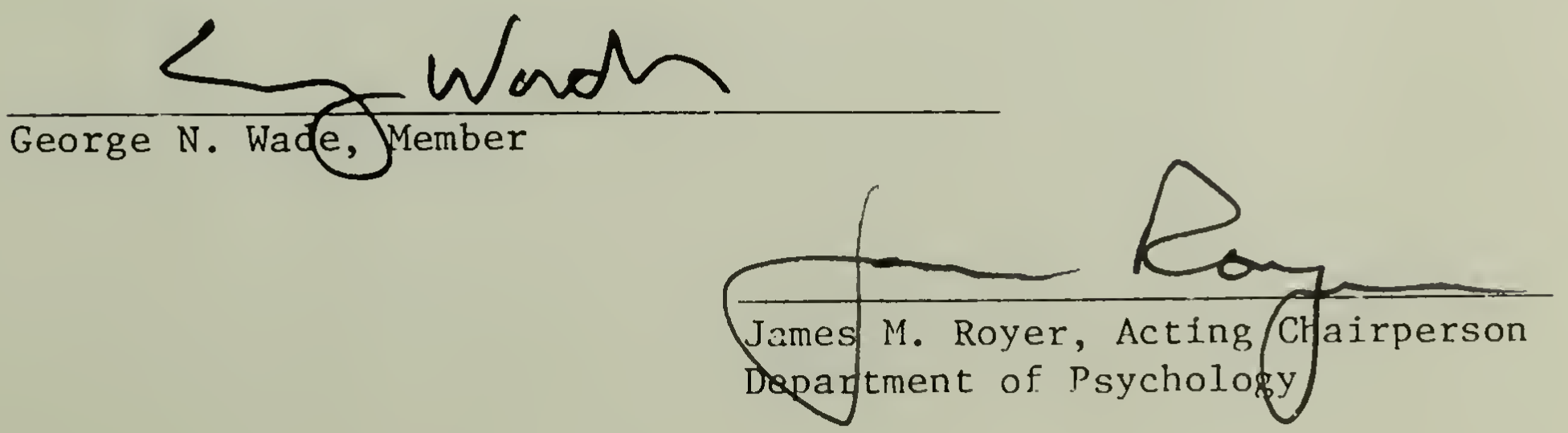




\section{DEDICATION}

This is dedicated to all the tollbooth workers on the Mass Turnpike without whose tireless devotion, through snow, rain, fog, traffic, and the independent trucker's strike, this thesis would not have been commuted.

Also, to my beloved husband Mitch, who was somewhat supportive. 
I am indebted to my adviser Dr. Jerrold S. Meyer for his constant guidance and support, his inspiration and instruction, and his unlimited patience.

I am also grateful to Dr. Melinda A. Novak and Dr. George Wade for serving as my thesis committee and providing good advice, insightful suggestions and encouragement.

A special note of thanks goes to my friends for their moral support and good will, most notably, Hank Heller, who has made many helpful comments concerning this work.

Thanks are also due to Christina Decoteau for helping with the preparation of this manuscript. 


\title{
ABSTRACT
}

A Role for Serotonin in the Hypothalamic-Pituitary-Adrenal Response to Insulin Stress

May 1983

\author{
Rachel Yehuda, B.A., Touro College \\ M.S., University of Massachusetts \\ Directed by: Professor Jerrold S. Meyer
}

Controversy exists concerning the possible involvement of serotonin in the pituitary-adrenocortical response to stress. In the present research, a variety of physiological and pharmacological manipulations were used in male rats to study the role of this newrotransmitter in the adrenocortical response to insulin-induced hypoglycemia. First, the effect of insulin stress on hypothalamic 5-HT metabolism was examined, and an increased turnover was found as determined by an enhanced accumulation of 5-HT following monoamine oxidase inhibition. The corticosterone response to insulin was potentiated by prior administration of L-tryptophan, and blocked by pretreatment with valine, an amino acid that competes with tryptophan for transport across the blood-brain barrier. Treatment with the 5-HT receptor blocker methysergide, or serotonin depletion by intraventricular injection of 5,7-dihydroxytryptamine significantly attenuated the insulin-induced rise in circulating corticosterone. It therefore appears that the pituitary-adrenal response to insulin 
is mediated at least in part, by 5-HT, and may be dependent on increased uptake of tryptophan by the brain. 
TABLE OF CONTENTS

DEDICATION

ACKNOWLEDGEMENT

ABSTRACT

LIST OF FIGURES

Chapter

I. INTRODUCTION . . . . . . . . . . . . . . . . 1

The HPA Axis . . . . . . . . . . . . . . . . . 1

Techniques used to study serotonergic regulation of HPA hormone release... . . . . 3

In Vitro studies of hypothalamic CRH secretion in response to $5-\mathrm{HT}$ and 5-HT altering drugs.............. . 3

Studies on the effect of 5-HT and 5-HT altering drugs on HPA hormone secretion in unstimulated animals . . . . . . 5

5-HT administration . . . . . . . . . . 5

Administration of 5 -HT precursors . . . . . . 6

Effect of serotonergic drugs . . . . . . . . 9

Effect of 5-HT and 5-HT altering drugs under conditions where the HPA system has been stimulated .............. 10

Human studies . . . . . . . . . . . . . 10

Animal studies . . . . . . . . . . . . . 11

The effect of stress on 5-HT brain metabolism ................. 13

Interactions of catecholaminergic neurotransmitters .............. 18

Score and purpose . . . . . . . . . . . 20

II. METHODS AND MATERIALS . . . . . . . . . . . . . 21

General methods . . . . . . . . . . . . 21

Experiment I: Characterization of the corticosterone and glucose response to insulin stress... . . . . . . . . . . . . 21

Experiment II: The effect of insulin stress on hypothalamic 5-HT turnover .. . . . . . . 22 
Experiment III: The effect of physiological
serotonergic manipulations on the
corticosterone response to insulin stress. . . . 23
Experiment IV: The effect of pharmacological
manipulations on the corticosterone
response to insulin stress . . . . . . . . . . . 24
Serotonin determination . . . . . . . . . . . . 25
Radioimmunoassay . . . . . . . . . . . . . . . . 27
Glucose analysis . . . . . . . . . . . . . . . . 28
Data analysis....................... 29

III. RESULTS . . . . . . . . . . . . . . . 30

Experiment I . . . . . . . . . . . 30

Experiment II . . . . . . . . . . . . 30

Experiment III . . . . . . . . . . . 36

Experiment IV . . . . . . . . . . . . 36

IV. DISCUSSION . . . . . . . . . . . . 48

BIBLIOGRAPHY • . . . . . . . . . . . . 56 
1. Dose-dependent changes in serum corticosterone and glucose concentrations following insulin . . . . . . . 31

2. Time-course effect of insulin on serum corticosterone . . . . . . . . . . . . . . . 32

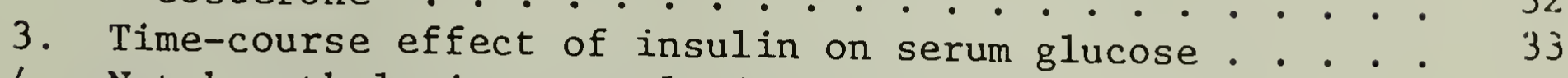

4. Net hypothalamic accumulation following pargyline .......... . . . . . . . . 35

5. Effect of tryptophan pretreatment of serum corticosterone response to insulin stress :. . . . . 38

6. Effect of valine pretreatment on serum corticosterone response to insulin stress . . . . . . . . . 40

7. Effect of methysergide on the serum corticosterone response to insulin stress . . . . . . . . . . . 42

8. Effect of 5,7 -DHT on hypothalamic 5 -HT content 10 days after the intraventricular injection of 5,7-DHT ..................... . . . 45

9. Effect of 5,7 -DHT on the serum corticosterone
response to insulin 


\section{H A P T E R I}

\section{INTRODUCTION}

Although many neurotransmitters are thought to play a role in regulating the hypothalamic-pituitary-adrenal (HPA) axis in response to stress, investigators to date cannot completely agree on what these neurotransmitters are, and the relative contribution of each. There is even controversy concerning the excitatory or inhibitory actions of the neurotransmitters which have been suggested to regulate this endocrine system. In order to understand the controversies which have ensued over the past two decades concerning the neural regulation of the hypothalamic-pituitaryadrenocortical system, it is necessary to briefly review some of the characteristics of this system as well as the limitations of the methods and techniques which have been used to study it.

The HPA axis. The hypothalamus receives various neural inputs which control the secretion of corticotropic releasing hormone (CRH), a 41-amino acid peptide (Vale et al., 1981). This peptide is released from specialized $\mathrm{CRH}$-containing neurons which have been detected in the anterior parvocellular region of the paraventricular nucleus complex in the rat hypothalamus as well as in the median eminence (Bloom et al., 1982). CRH reaches the anterior 
pituitary via the hypophyseal portal circulation, where it stimulates the synthesis and release of adrenocorticotropic hormone (ACTH). In response to ACTH, the adrenal glands produce and release glucocorticoids (corticosteroids).

In addition to stress-induced hormone release, other aspects of the HPA system involve the regulation of basal circadian CRH release and feedback suppression of $\mathrm{CRH}$. The neural inputs which regulate these different aspects of HPA hormone secretion are thought to be at least partially independent of one another. Evidence suggests that basal circadian periodicity involves regulation by the suprachiasmatic nucleus, whereas feedback regulation occurs via limbic system inputs (for review, see Krieger, 1977).

While the following discussion will focus mainly on the regulation of the HPA stress-response, these other aspects of HPA hormone secretion need to be mentioned because of their potential effects on the corticosteroid response to stress. For example, stress induced hormone release may differ according to the relative amounts of corticosteroids present in the circulation at the time of stress exposure (Vernikos-Danellis \& Heybach, 1980). Adrenal sensitivity to ACTH also varies in response to such factors as time of day (Dallman et al., 1976). Thus, although the central mechanisms which regulate circadian rhythmicity may be distinct from those regulating the stress response, stress-induced adrenocortical secretion may be affected by diurnal variation. Additionally, it is important to note that these characteristics may share 
one or more neurotransmitters, and as such may shed light on stressinduced HPA function. Indeed, evidence has been accumulating to suggest the involvement of one particular neurotransmitter in all areas of HPA function. This neurotransmitter is serotonin (5-HT).

Techniques used to study serotonergic regulation of HPA hormone release. A variety of techniques have attempted to elucidate a role for 5-HT in hypothalamic-pituitary-adrenocortical functioning in response to stress. These studies fall into four categories:

* In vitro studies of hypothalamic CRH secretion in response to 5-HT and 5-HT altering drugs

* studies on the effect of 5-HT and 5-HT altering drugs on HPA hormone secretion in unstimulated animals

* studies on the effect of 5-HT and 5-HT altering drugs under conditions where the HPA system has been stimulated * studies on the ability of stress to affect brain 5-HT metabolism.

In vitro studies of hypothalamic CRH secretion in response to 5-HT and 5-HT altering drugs. A number of investigators have measured CRH activity in isolated hypothalami of adrenalectomized rats in response to various neurotransmitters and drugs. In general these studies have been consistent in obtaining evidence which supports a stimulatory role for 5-HT. Jones, Hillhouse and Burden (1976) and Buckingham and Hodges (1979) found that 5-HT could stimulate $\mathrm{CRH}$ release in a dose-dependent manner. This effect was 
antagonized by the 5-HT receptor blocker methysergide.

In a more recent study Holmes et a1. (1982) have found that 5-HT induced CRH activity could be potentiated by chlorimipramine or $\mathrm{d}$-fenfluramine, two drugs which are thought to cause an increased concentration of 5-HT in the synaptic cleft. (The former drug is a known 5-HT reuptake inhibitor, and the latter drug is presumably a 5-HT releasing drug.) In addition, treatment with 5,7-dihydroxytryptamine (5,7-DHT), a 5-HT neurotoxin, enhanced CRH secretion in response to 5-HT administration -- an effect which is probably due to increased sensitivity of 5-HT postsynaptic receptors following 5,7-DHT administration.

While a 5-HT stimulation can be clearly seen in these studies, there is some dispute as to the relative importance of other neurotransmitter systems which may or may not be influencing 5-HT induced CRH secretion. For example in the aforementioned study by Jones et a1., 5-HT stimulated CRH release could be attenuated by two cholinergic antagonists, hexomethonium and atropine. Jones et al. therefore concluded that while 5-HT acts to stimulate hypothalamic $\mathrm{CRH}$ secretion, such stimulation may be mediated through a cholinergic interneuron. This conclusion is consistent with the finding of Hillhouse, Burden and Jones (1974) that acetylcholine (ACh) itself stimulates the release of $\mathrm{CRH}$. Buckingham and Hodges were able to replicate this latter finding, however they were unable to block 5-HT induced CRH release with anticholinergic drugs. Thus, they concluded that cholinergic cells 
may be involved in $\mathrm{CRH}$ regulation but not necessarily in the capacity of interneurons.

In the study of Buckingham and Hodges ACh induced CRH release was antagonized not only by anticholinergic drugs, but by the neurotransmitters norepinephrine (NE) and gamma-aminobutyric acid (GABA). These studies taken together provide evidence for 5-HT and other neurotransmitter receptors in the hypothalamus which regulate $\mathrm{CRH}$ release, and suggest, at least under the specified in vitro conditions, that 5-HT functions to stimulate CRH secretion.

Studies on the effect of 5-HT and 5-HT altering drugs on HPA hormone secretion in unstimulated animals.

5-HT administration. The effect of intracranial injections on pituitary-adrenal activity has been studied in several species. Krieger and Krieger (1970) observed a stimulation of pituitary adrenocortical activity with intraventricular injections of 5-HT in cats. In guinea pigs, 5-HT injections into several brain areas elevated plasma 17-hydroxycorticosteroids in both intact animals and in those which had received midbrain transections (Naumenko, 1968). This latter result indicated that 5-HT induced HPA stimulation does not involve ascending pathways below the level of the transection.

In a subsequent study, the same investigator (Naumenko, 1.969) showed that 5-HT injections into different brain regions may cause differences in HPA functioning. In this study, a rise 
in plasma corticosteroids was seen in response to 5-HT injections to the ventral hippocampus, while 5-HT administered to the dorsal hippocampus produced a $20 \%$ decrease in plasma 17 -hydroxycorticosteroids. Similarly, an increase in corticosteroids was seen when 5-HT was injected into the septum while a decrease was seen in the amygdala. The results of this study suggest that different 5-HT pathways may act in a different capacity to mediate pituitaryadrenocortical activity. This is consistent with the idea of independent neural inputs regulating HPA activity.

Vermes and Telegdy (1972) showed that 5-HT intraventricular injections had no effect on pituitary-adrenal activity in rats. It is therefore difficult to draw firm conclusions from these studies, however the majority are consistent with the in vitro experiments which support a primary stimulatory role for 5-HT in HPA hormone secretion.

Administration of 5-HT precursors. L-5-hydroxytryptophan (5-HTP) is the immediate precursor to 5-HT and has been used to study the involvement of 5-HT in pituitary-adrenal functioning. In rodents doses of $50 \mathrm{mg} / \mathrm{kg}$ (Fuller, Snoddy \& Molloy, 1976; Meyer, Buckholtz \& Boggan, 1978) to $100 \mathrm{mg} / \mathrm{kg}$ (Popova, Maslova \& Naumenko, 1972) 5-HTP produced elevations in circulating corticosteroids. This effect was potentiated by a monoamine oxidase (MAO) inhibitor (a drug which prevents the degredation of 5-HT and catecholamines into their precursors by the enzyme MAO) (Fuller \& Clemens, 1981). This suggests a hormone elevation due to 5-HT, 
but does not rule out the possibility of an involvement of other monoamines such as NE and dopamine (DA), since MAO inhibition may have an effect on the release of these neurotransmitters.

Fluoxetine, a 5-HT reputake inhibitor significantly potentiated the 5-HTP induced rise in circulating corticosterone (Fuller, Snoddy, \& Molloy, 1976). This clearly suggests a hormone elevation due to serotonergic activity. Attempts have also been made to attenuate the increase in corticosterone seen with 5-HTP. Meyer, Buckholtz and Boggan (1978) found that metergoline and cyproheptadine antagonized the effect of 5-HTP in mice. Steiner and Grahame-Smfth (1979) found no effect with those particular 5-HT receptor blockers in rats, but did see an antagonism of the 5-HTP effect using mianserin, a less potent receptor blocker which may be acting at a different 5-HT receptor site. Meyer and co-workers also found that the 5-HTP effect was significantly attenuated by peripheral decarboxylase inhibitors in rats (submitted for publication) and mice (1978), but others have not been able to replicate these findings (Fuller, 1981; Steiner \& Grahame-Smith, 1979). In general, the success of 5-HT agents in altering the corticosteroid response to 5-HTP suggests a 5-HT involvement in pituitary-adrenal hormone regulation. One problem in using this precursor, however, is that the enzyme which converts 5-HTP to 5-HT is nonspecific and is found in other neurons, particularly catecholaminergic ones. Therefore, administration of 5-HTP can result in $5-\mathrm{HT}$ production in brain areas that don't usually 
contain 5-HT. This means that corticosterone changes in response to 5-HTP do not necessarily reflect the normal physiology of serotonergic HPA regulation.

For this reason, some experimentors argue that it is more desirable to use the dietary precursor of 5-HT, tryptophan. Studies of L-tryptophan administration in man have been somewhat successful in demonstrating a role for 5-HT in HPA hormone regulation but the nature of this role remains obscure: Imura, Nakai and Yashimi (1973) demonstrated that tryptophan at a high dose (150 mg/kg) increases pituitary-adrenal activity, while Woolf and Lee (1977) showed that tryptophan produced a decrease in baseline cortisol levels at the low dose of $20 \mathrm{mg} / \mathrm{kg}$.

In animals it has been necessary to give very high doses of tryptophan to obtain a rise in corticosterone since only a small percentage of peripherally injected tryptophan enters the brain (Fuller, 1981). However, investigators have not been able to potentiate this response with fluoxetine or attentuate it with pchlorophenylalanine (PCPA), a potent 5-HT depleter (Fuller, 1980). Thus, it is unclear whether the effect of very high doses of tryptophan in elevating circulating corticosteroids is serotonergically mediated. It is unfortunate that there are so many methodological limitations in using 5-HT precursors to ascertain the role of 5-HT in HPA hormone regulation; other 5-HT pharmacological manipulations which have been free from these particular problems have been able to address this issue more clearly. 
Effect of serotonergic drugs. Quipazine, a direct receptor stimulant caused dose-dependent increases in circulating corticosterone in rats (Fuller, Snoddy \& Clemens, 1978) and mice (Meyer, Buckholtz \& Boggan, 1978). This effect was antagonized by metergoline in rats (Fuller \& Snoddy, 1979), but not in mice (Meyer, Buckholtz \& Boggan, 1978). The quipazine induced rise in corticosterone was still seen in rats pretreated with 5,7-DHT (Fuller, 1981). This result was expected, as quipazine acts on post-synaptic 5-HT receptors.

The 5-HT releasers fenfluramine and p-chloramphetamine (PCA) also increased levels of corticosteroids (Fuller \& Snoddy, 1980). The effect of PCA was prevented by PCPA pretreatment, and also by fluoxetine (Fuller \& Snoddy, 1980). PCPA depletes neurons of 5-HT making small amounts of this neurotransmitter available for release. Fluoxetine inhibited the uptake of PCA into serotonergic neurons, making them unable to affect 5-HT release.

Fluoxetine also elevated levels of corticosterone (Fuller, Snoddy \& Molloy, 1976), presumably by maintaining elevated levels of 5-HT in the synapse and causing increased stimulation of postsynaptic neurons.

Despite the rise in corticosterone seen with serotonergic agonists, antagonists such as receptor blockers, depleters and neurotoxins have not been able to lower baseline corticosterone levels. They have only been able to in some cases antagonize the elevation of corticosteroids in response to agonists. In fact, 
Meyer et al. (1978) have found that cyproheptadine and metergoline alone actually elevated corticosterone levels in mice.

That 5-HT antagonists attenuate corticosterone responses only in a state of hormone elevation suggests that the HPA system may respond differently to neurotransmitters, particularly 5-HT, in different ways depending on the system's level of excitation. If this is true, 5-HT may mediate hormone secretion differently in response tostress, or under conditions where the pituitary-adrenocortical system is stimulated. The next section will review the pharmacological data on the effect of 5-HT in stimulated animals, and will pay particular attention to its inconsistencies with the aforementioned.

Effect of 5-HT and 5-HT altering drugs under conditions where the HPA system has been stimulated. The results of studies using stressful manipulations or other situations in which baseline pituitary-adrenal activity is elevated have been difficult to interpret for several reasons. The primary one seems to be the lack of consistency between data obtained in human and animal studies.

Human studies. In general, human studies have been consistent with each other, and with both the in vitro studies and studies of unstimulated organisms. In most cases, results have confirmed a stimulatory role for 5-HT. For example, the 5-HT receptor blocker metergoline reduced increased ACTH levels seen in response to insulin stress (Cavagnini et al., 1976). 
In other situations (which are not accurately considered stress-induced) where the HPA system is stimulated, other 5-HT antagonists have produced similar effects. In addition to metergoline, methysergide (Cavagnini et al., 1975) and cyproheptadine (Plonk \& Feldman, 1976) were effective in lowering increased ACTH levels following metyrapone treatment. (Metyrapone is an adrenocortical antagonist which interferes with the synthesis of corticosteroids, and as such eliminates feedback inhibition of corticosteroids on ACTH. This drug is often used to determine whether hypersecretion of corticosteroids is due to adrenal tumors or pituitary malfunctions.)

Cyproheptadine was also effective in reducing symptoms of two clinical endocrinopathies, Cushing's disease, which is characterized by adrenocortical hypersecretion (Krieger, Amorosa \& Linisk, 1975), and Nelson's syndrome, in which excessive ACTH secretion occurs as a result of bilateral adrenalectomy treatment in Cushing's patients (Krieger \& Luria, 1976). These studies are consistent with the idea that the role of 5 -HT in the adrenocortical response to stress is stimulatory.

Animal studies. Results obtained from animal studies have not been consistent with the human data. Some investigators have reported inhibitory effects of 5-HT on the pituitary-adrenal response to stress. In rats, for example, the increase in circulating ACTH levels produced by ether was blocked by pretreatment with tryptophan, and enhanced by PCPA (Vernikos-Danellis \& 
Berger, 1973). Intraventricular injection of 5-HT (while reported by these investigators to have no effect on baseline HPA secretion) prevented the corticosterone increase in response to surgical stress (Telegdy \& Vermes, 1976).

Other investigators, however, have failed to alter the adrenocortical response to stress using serotonergic drugs. The 5-HT reuptake inhibitor fluoxetine did not influence plasma corticosterone levels following either swim stress or insulin stress (Fuller \& Snoddy, 1977). PCPA had no effect on increased plasma corticosterone levels seen with hypoxia (oxygen deprivation) or hypercapnia (oxygen deprivation + carbon dioxide administration) (Marotta et al., 1976), while 5-HT depletion produced by the neurotoxin 5,7-DHT or electrolytic lesions of the midbrain raphe did not alter the ACTH response to ether (Karteszi, 1981).

It would be tempting at this point in the discussion to simply conclude that 5 -HT stimulates the pituitary-adrenal system in animals at a baseline hormone level, and inhibits or has no effect on HPA hormones in response to stress. Unfortunately, studies of the effect of 5-HT on animals in response to stress are contradictory, since some studies fail to find any role for 5-HT. Before accepting the aforementioned conclusion it is necessary to further investigate the effect of 5-HT manipulations on pituitaryadrenal hormones in response to stress.

With respect to the disparity between studies of stimulated humans and animals it appears that 5-HT regulation may function 
in a different manner in man and rodents. Ordinarily, this would be an acceptable conclusion, however, we shall now look at studies on the effect of stress on 5-HT metabolism in animals which indicate a role for 5-HT which is quite in contradiction with the pharmacological, studies which have just been discussed.

The effect of stress on 5-HT brain metabolism. Investigators have taken two basic approaches to measure the effect of stress on brain 5-HT. One method, used particularly in the earlier studies, has been to administer a stressor to an animal, and then simply measure the content of this neurotransmitter in either the whole brain or various parts of the brain. In these studies, elevated levels of 5-HT were seen as an indication of increased 5-HT synthesis. Many of these studies showed that stress had no effect on 5-HT, and concluded, therefore, that this neurotransmitter was not involved in the regulation of the stress response. Some investigators, however did see increased concentrations of 5-HT with stress. De Schaapdryver, Preziosi and Scapagnini (1969), for example, observed a $10 \%$ increase in whole brain 5-HT (and a simultaneous drop in NE and DA).

In 1966, a more sophisticated method of looking at 5-HT metabolism was described by Tozer, Neff and Frodie (1966). This method is based on assuming a steady state kinetics of the 5-HT system. That is, the rate at which tryptophan and 5-HT are converted to $5-\mathrm{HT}$ is considered to be equal to the rate of conversion 
of 5-HT to its metabolite 5-HIAA. This situation is characterized as an open system; under these conditions the level of brain 5-HT remains constant and the rate of formation of 5-HT is equal to the rate of turnover. Investigators can estimate the rate of 5-HT synthesis by pharmacologically preventing the conversion of 5-HT to its metabolite 5-HIAA and measuring the (exponential) decline of 5-HIAA. By plotting the logarithms of 5-HIAA concentrations at various time points and using the slope of the line to determine a rate constant, one could express the rate at which 5-HT has been synthesized (i.e., turnover) from the product of the rate constant of 5-HIAA decline and the normal 5-HIAA level. Alternatively, one can measure the accumulation of 5-HT after inhibiting the formation of 5-HT to 5-HIAA (Neff \& Tozer, 1968). After such treatment 5-HT will accumulate in the brain at a rate proportional to its synthesis. This method is based on assuming a lack of feedback inhibition on tryptophan hydroxylase by 5-HT.

Bliss, Thatcher and Ailion (1972) looked at several types of stressors and their effect on 5-HT content and turnover. There was no change reported in 5-HT content with foot shock in mice or rats, but increased 5-HT turnover was seen in whole brain. The lack of altered 5-HT content was interpreted by Bliss, Thatcher and Ailion to mean that brain levels of 5-HT remain stable even during increased 5-HT synthesis, a phenomenon which may explain the failure of some investigators to observe changes in 5-HT content. Increased 5-HT turnover was also seen during sleep 
deprivation stress, swim stress, and psychosocial stress, which involved exposing rat colonies to different strains of rats in a noval environment.

Increased $5-\mathrm{H}_{\dot{i}}$ turnover in response to stress was also observed by several other investigators. Increased rates of 5-HT turnover during restraint stress have been observed in whole brain (Kenneth \& Joseph, 1982), in the cerebral cortex (Morgan, Rudeen \& Pfeil, 1975) and in the hypothalamus (Mueller et al., 1976). Food deprivation and novelty stress also increased whole brain turnover (Curzon, Joseph \& Knott, 1972; Knott, Joseph \& Curzon, 1973; Knott, Hutson \& Curzon, 1977).

The different methodological approaches discussed earlier which attempted to determine the role of 5-HT in stress met with contradictory results. This line of research is no exception. While the above studies are clearly consistent with a stimulatory role for 5-HT in pituitary-adrenocortical function in response to stress in rats, other experiments have produced data leading to an opposite conclusion.

Telegdy and Vermes (1976) tested many types of stressors for their effect on 5-HT turnover in brain hypothalami. Some stressors, like cold stress, restraint or two minute exposure to ether caused rapid changes in both corticosterone levels reaching a peak, and 5-HT levels reaching a maximum descent at 30 minutes. By 90 minutes following stress onset, levels of 5-HT started to ascend, ultimately overshooting baseline levels. Other stressors such as 
electric shock or surgical stress produced corticosterone responses which remained high even 90 minutes after the onset of stress, although levels of 5-Hi', which were initially decreased, returned to normal by that time. A third type of stressor, such as formalin stress, produced low hypothalamic 5-HT levels and high corticosterone concentrations which lasted beyond 90 minutes. This study suggests that the very nature of the stressor may affect the involvement of 5-HT in hormone regulation.

The depletion of 5-HT seen when HPA hormone levels are elevated suggests an inhibitory role for 5-HT. According to Telegdy and Vermes, under normal conditions 5-HT exerts an inhibition on the hypothalamus, causing low baseline corticosterone levels. During stress, 5-HT is depleted, and inhibition is removed, thus increasing corticosterone plasma concentrations. The model further proposes that the elevated levels of corticosterone subsequently restore the depleted hypothalamic 5-HT. When 5-HT levels, and therefore, the inhibition due to 5-HT are restored, corticosterone levels return to their low baseline levels. To lend further support to this theory, the authors administered $1 \mathrm{mg} / \mathrm{kg}$ i.p. corticosterone to rats and found a rapid increase in 5-HT concentrations in the hypothalamus, mesencephalon and amygdala. Administration of $20 \mathrm{\mu g} 5-\mathrm{HT}$ intraventricularly diminished the rise in plasma corticosterone seen in response to surgical stress.

It is difficult, indeed, to account for the contradictory results seen in these experiments. What these inconsistencies 
suggest, however, is that determining a role for 5-HT is perhaps more complicated than simply deciding between its actions as an inhibitory or an excitatory neurotransmitter in response to stress. One approach to take in explaining some of the inconsistencies is to point out that scientists have been at somewhat of a disadvantage in their studies since 5-HT pharmacology is not as far advanced as the pharmacology of certain other transmitters such as the catecholamines.

Part of the lack of knowledge regarding 5-HT pharmacology is directly related to an incomplete understanding of 5-HT receptors. The existence of multiple 5-HT receptors in brain was suggested as early as 1967 by studies in the cerebral cortex, where microiontophoretically applied 5-HT produced either excitation or inhibition in some neurons (Roberts \& Straughan, 1967). Recent data suggests that there are at least three different types of 5-HT receptors in the brain (Aghajanian, 1981). Two 5-HT receptors are post-synaptic; one type is thought to be excitatory (Type 2) while the other suppresses neuronal activity (Type 1). Located presynaptically are 5-HT autoreceptors which mediate 5-HT inhibition. Different drugs may act selectively at these different 5-HT receptor sites, but these interactions are not fully understood. In addition, it is not clear whether 5-HT receptor types mediate different actions of $5-\mathrm{HT}$ in response to stress.

It is also necessary to point out that the range of methodological techniques which have been used in various studies 
has made it more difficult for researchers to obtain similar results. For example, in turnover studies, experimenters have not consistently looked in the same brain regions. In pharmacological studies, investigators have not always used the same drugs to alter HPA hormone secretion. In stress studies, different stressors have been used. This latter factor may particularly account for much of the variability in the data since different types of stressors influence 5-HT differently, and 5-HT may act in a different capacity in response to different stressors. Another important factor to consider is that many studies have suggested an involvement of other neurotransmitters either directly or indirectly by virtue of a failure of serotonergic manipulations to influence pituitary-adrenal activity. Given the complexity of interaction between neurotransmitters, it is expected that some contradictions will arise. Certainly it is important to consider how other neurotransmitters may affect HPA hormone secretion. Some of the aforementioned studies have indicated a cholinergic involvement in HPA regulation. There has also been increasing evidence for the involvement of catecholaminergic systems.

Interactions of catecholaminergic neurotransmitters. Administration of the DA agonist pergolide, elevated serum corticosterone concentrations in rats (Fuller \& Snoddy, 1981). Such stimulation was prevented by pretreatment with DA antagonists. Intravenous 
administration of the DA precursor L-dopa similarly elevated levels of cortisol in humans (Wilcox et ai., 1975). On the other hand, i.v. pulse injections of the DA blocker haloperidol enhanced resting plasma cortisol levels (Balestreri, Bertolini, and Castello, 1979), a result consistent with the effect of L-dopa in attenuating the plasma cortisol response to insulin-induced hypoglycemia seen by the same investigators. Although these latter results suggest an inhibition by DA of pituitary-adrenocortical hormone secretion, the authors suggest that haloperidol may be acting on DA postsynaptic (self-inhibiting) neurons, and therefore may actually be increasing DA synthesis. Thus, it is not completely clear what the action of DA may be in CRH regulation.

Studies on the effect of NE have been somewhat less ambiguous and have shown that $\mathrm{NE}$ acts to inhibit $\mathrm{CRH}-\mathrm{ACTH}$ secretion. For example, large doses of NE have been found to prevent the increase in ACTH normally seen in response to surgical stress (Van Loon et a1., 1971). NE antagonists such as reserpine, a NE depleter (Scapagnini et al., 1972) and alpha-methyl-p-tyrosine, an NE synthesis inhibitor (Van Loon et al., 1971) seem to enhance stressinduced ACTH secretion.

These are just a few studies which indicate an involvement of catecholamines in HPA regulation of hormone secretion. Here too, it is unclear to what extent and in what capacity, these neurotransmitters are acting. In many studies, catecholamines exert direct action on HPA hormone secretion, however, in addition to 
this direct effect, these neurotransmitters may exert action on 5-HT which could directly affect 5-HT regulation of HPA functioning.

Scope and purpose. Despite the fact that studies concerning the neural regulation of stress continue to accumulate, there is no clear picture of the factors which regulate HPA hormone secretion in response to stress. Even the experimenters who have investigated a role for 5-HT in the regulation of this axis are still in debate over whether 5-HT acts to stimulate or to suppress this axis. In view of the controversial results cited above, the following experiments were performed in an attempt to clarify the role of $5-\mathrm{HT}$ in the pituitary-adrenal response to stress. The stress of insulin-induced hypoglycemia was chosen because this stressor is easily quantified and manipulated, it represents a physiological challenge to the organism, and the stress response can (through measurements of blood glucose) be assessed independently of pituitary-adrenal activity. 
General methods. Two hundred twenty six adult male Wistar rats were purchased from Charles River or bred in our laboratory. Animals were housed singly in a colony room under a 14:10 1ightdark cycle (lights on at 0600 hours) and were fed Purina lab chow and tap water ad 1ibitum. The rats weighed $225-350 \mathrm{~g}$ at the time of experimentation.

All experiments took place between 0800 and 1100 hours when the serum corticosterone concentration is low in the normal diurnal rhythm. All animals were fasted approximately 16 hours before receiving insulin or vehicle. At the appropriate time after drug administration, animals were quietly removed from the colony room and killed by decapitation at intervals of at least 2 minutes. Trunk bloods were collected and allowed to clot on ice. Bloods were then centrifuged and the sera aspirated and frozen at $-40^{\circ} \mathrm{C}$ for corticosterone determination by radioimmunoassay. In some cases, serum glucose analyses or hypothalamic 5-HT determinations were also performed.

Experiment I: Characterization of the corticosterone and glucose response to insulin stress. Dose-response and time-course studies were carried out in order to determine the parameters of both the 
corticosterone response to insulin and the corresponding glucose levels. In the dose-response study, fasted rats were injected subcutaneously (s.c.) with one of 5 doses of insulin (Squibb, U40) ranging from $0.125-.250 \mathrm{U} / \mathrm{kg}$ or saline, and were killed 40 minutes later.

For the time-course study, fasted rats were killed 0,20 , 40,60 , and 80 minutes after the s.c. injection of $.20 \mathrm{U} / \mathrm{kg}$ insulin or saline. In both cases, serum corticosterone and glucose were analyzed.

Experiment II: The effect of insulin stress on hypothalamic 5-HT turnover. Changes in 5-HT turnover after insulin or saline were measured in order to determine whether the metabolism of this neurotransmitter is altered in response to stress. Turnover was measured by preventing the degradation of 5-HT into 5-HIAA and allowing 5-HT to accumulate in the hypothalamus. This method is similar to that of Tozer and Neff (1968) and is based on assuming a lack of feedback inhibition by 5-HT on tryptophan hydroxylase, the enzyme which converts tryptophan to 5-HTP.

In this experiment, MAO was inactivated with pargyline. Fasted animals were injected intraperitoneally (i.p.) with $75 \mathrm{mg} / \mathrm{kg}$ pargyline (Sigma Chemical Co.) and then 5 minutes later either killed immediately or injected with $0.20 \mathrm{U} / \mathrm{kg}$ insulin or saline. The latter two groups were killed 45 minutes after pargyline administration. 5-HT turnover was measured by the accumulation of 
5-HT as a result of the pargyline treatment. Hypothalamic 5-HT concentrations were determined in all animals by the method described below.

Experiment III: The effect of physiological serotonergic manipulations on the corticosterone response to insulin stress.

It was of interest to determine whether the rise in corticosterone associated with insulin stress is a result of increased availability of the 5-HT precursor tryptophan to the brain. In this study the normal plasma concentrations of tryptophan and another amimo acid, namely valine, were altered. Valine is a neutral amino acid that has previously been shown to compete with tryptophan for entrance across the blood-brain barrier (Pardridge, 1979). The administration of tryptophan and valine are in a sense physiological serotonergic manipulations because of their potential ability to alter the availability of tryptophan, and therefore, of 5-HT synthesis.

In the first part of this study, L-tryptophan (Sigma Chemical Co.) was tested for its ability to potentiate the effect of a submaximal dose of insulin on circulating corticosterone levels. Fasted animals were pretreated s.c. with $200 \mathrm{mg} / \mathrm{kg}$ tryptophan 20 minutes before receiving $0.150 \mathrm{U} / \mathrm{kg}$ insulin or saline. Next, animals were pretreated s.c. with $200 \mathrm{mg} / \mathrm{kg}$ valine 20 minutes before receiving $0.20 \mathrm{U} / \mathrm{kg}$ insulin or saline. Blood samples were obtained in the usual manner 40 minutes following insulin 
treatment.

Experiment IV: The effect of pharmacological manipulations on the corticosterone response to insulin stress. Two pharmacological manipulations were employed to investigate the effect of 5-HT antagonism on the corticosterone response to insulin. The first study attempted to determine whether the insulin-induced rise in corticosterone could be attenuated with a drug that blocks serotonergic action. Fasted animals were pretreated i.p. with $5 \mathrm{mg} / \mathrm{kg}$ methysergide (Sandoz, Inc.) a serotonergic receptor blocker, 1 hour before receiving $0.20 \mathrm{U} / \mathrm{kg}$ insulin or saline. Animals were killed 40 minutes following this latter injection.

Next, brain 5-HT was depleted using the potent 5-HT neurotoxin 5,7-DHT (Sigma Chemical Co.). 5,7-DHT decreases brain 5-HT by about $70-80 \%$ when measured 8-12 days after administration (Baumgarten et a1., 1975). Rats were anesthetized with Equithesin (Jensen Salsber Laboratories), placed in a stereotaxic instrument, and then injected intraventricularly with $150 \mu \mathrm{g}$ of 5,7-DHT (free base) in $20 \mu 1$ of $0.1 \%$ ascorbic acid. Control animals received an equal volume of the ascorbic acid alone. Because 5,7-DHT can also produce a moderate depletion of brain NE, animals were pretreated i.p. with $25 \mathrm{mg} / \mathrm{kg}$ desipramine (Merrel Dow Research) 45 minutes before drug or vehicle injections. Desipramine is a potent inhibitor of NE uptake, and therefore prevents 5,7-DHT from entering noradrenergic neurons (Bjorklund, Baumgarten \& 
Rensch, 1975). Ten days later, fasted animals were killed 40 minutes following the injection of $0.20 \mathrm{U} / \mathrm{kg}$ insulin or saline. Blood samples were collected for subsequent corticosterone determination and hypothalami dissected and assayed for their 5-HT content.

Serotonin determination. Following decapitation, brains were removed and hypothalami were rapidly dissected over ice. A rostral coronal cut was made from the ventral side of the brain at the level of the suprachiasmatic nuclei, and a caudal transection was made immediately posterior to the mammillary bodies at the level of the interpeduncular fossa. The hypothalamus was removed from its lateral boundaries, the entorhinal cortex, with two $5 \mathrm{~mm}$ cuts. A final horizontal cut separated the hypothalamus from the overlying thalamus. Each hypothalamus was weighed, and then homogenized in a total volume of $2.0 \mathrm{ml}$ of ice-cold $.4 \mathrm{~N} \mathrm{HClO}_{4}$ to deproteinize the tissue. In addition, $50 \mu 1$ of $10 \%$ disodium ethylenediamine tetra-acetate (EDTA) was added to the $\mathrm{HClO}_{4}$ to chelate any contaminating heavy metals during homogenization, and $50 \mu 1$ ascorbic acid was added to protect the 5-HT during extraction. Samples were centrifuged at $-5^{\circ} \mathrm{C}$ for 20 minutes at $30,000 \times \mathrm{g}$. Supernatants were decanted and were then brought up to a $\mathrm{pH}$ of $5.5-6.0$ using $\mathrm{KOH}$. One drop of $0.04 \%$ bromphenol blue in absolute ethanol was added to each tube to aid in the $\mathrm{pH}$ adjustment. Samples were recentrifuged for 5 minutes to remove 
the $\mathrm{KClO}_{4}$ precipitate. Supernatants were decanted and brought to room temperature, and were applied to $3 \times 20 \mathrm{~mm}$ columns of a weak cation exchange resin (Bio-Rex 70, Bio-Rad Laboratories) which had been cycled according to the manufacturer and then equilibrated in a $0.1 \mathrm{M}$ sodium phosphate buffer, $\mathrm{pH} 6.5$, containing $0.1 \% \mathrm{di}-$ sodium EDTA (Barches, Erdelyi \& Angwin, 1972). The columns were washed first with $1.5 \mathrm{ml} 0.02 \mathrm{M}$ phosphate buffer, $\mathrm{pH} 6.5 \mathrm{con}-$ taining $0.2 \%$ disodium EDTA, and then with $1.0 \mathrm{ml}$ deionized water, as described by Holman, Angwin and Barchas (1970). 5-HT was eluted with two $0.5 \mathrm{ml}$ aliquots of $2.5 \mathrm{~N} \mathrm{HCl}$, most of the 5-HT being recovered in the first eluate. Each 5-HT eluate was reacted with o-pthalaldehyde (OPT, Sigma Co.) (Maikel \& Miller, 1966) which had been repurified in our laboratory according to Jacobowitz and Richardson (1978). Stock solutions of $0.5 \mathrm{mg} / \mathrm{ml}$ OPT were made weekly and stored at $4^{\circ} \mathrm{C}$. On the day of each assay, a portion of this solution was diluted $1: 19$ in concentrated $\mathrm{HCl}$ to yield a working acidified OPT reagent. For the standards, a stock solution of 5-HT creatinine sulfate (Regis Chemical Co.) corresponding to $1.0 \mathrm{mg} / \mathrm{ml}$ free $5-\mathrm{HT}$ was made up in $0.01 \mathrm{~N} \mathrm{HCl}$ and stored at $4^{\circ} \mathrm{C}$ for up to 1 month. A standard curve was constructed for each assay by diluting the stock $5-\mathrm{HT}$ solution in $2.5 \mathrm{~N} \mathrm{HCl}$ to a final concentration of $900 \mathrm{ng} / \mathrm{ml}$. Appropriate volumes yielding 9-67.5 ng 5-HT were placed in assay tubes and were then reacted with the acidified OPT reagent. Samples and standards were heated at $100^{\circ} \mathrm{C}$ for 10 minutes, cooled to room temperature, and then read 
on a Perkin-Elmer \#1000 Spectrofluorometer at (uncorrected) excitation and emission wavelengths of $364 \mathrm{~nm}$ and $480 \mathrm{~nm}$ respectively. Unknowns were calculated from the standards using a least squares linear regression.

Radioimmunoassay. For the determination of serum corticosterone, each frozen serum sample was thawed and diluted 1:99 in $0.65 \mathrm{M}$ sodium buffer, $\mathrm{pH} 8.0$. Samples were heated at $75^{\circ} \mathrm{C}$ for 30 minutes to denature transcortin, an endogenous corticosterone binding globulin, and were then allowed to cool to room temperature.

For the preparation of standards, unlabeled corticosterone (Steraloids, Inc.) was dissolved in absolute ethanol, and appropriate volumes yielding 20,50,100,200,500 and $1000 \mathrm{pg}$ corticosterone were placed in clean assay tubes. Standards were then evaporated under $\mathrm{N}_{2}$ and redissolved in $50 \mu 1$ borate buffer.

The RIA utilized a ${ }^{3} \mathrm{H}$-corticosterone tracer $(92.0 \mathrm{Ci} / \mathrm{mmol}$, New England Nuclear) and an anticorticosterone antiserum (B3-163, Endocrine Sciences). ${ }^{3} \mathrm{H}$-corticosterone was diluted in absolute ethanol, stored at $-10^{\circ} \mathrm{C}$, and periodically repurified by sephadex LH-20 column chromotography (Murphy \& Diez D'Aux, 1975). The anticorticosterone antiserum was found to cross-react $0.4 \%$ with cortisol (based on $100 \%$ reactivity with authentic corticosterone) $4.9 \%$ with deoxycorticosterone, $0.7 \%$ with progesterone, and less than $0.1 \%$ with both testosterone and estradiol. The tracerantiserum mixture was prepared in a sodium borate buffer containing $0.2 \%$ bovine serum albumin (Sigma Co.) and $0.05 \%$ bovine gamma 
globulin (BGG) (Sigma Co.). BGG was added to increase the mass of precipitated protein in the ammonium sulfate step described below.

Two hundred $\mu 1$ of the trace-antiserum mixture was reacted with $50 \mu 1$ aliquots of the heat-denatured samples and standards (in duplicate). Each tube contained approximately 6000-7000 CPM of ${ }^{3} \mathrm{H}$-corticosterone and a final antiserum dilution of $1: 1500$. Tubes were incubated for 2 hours at room temperature, and were then precipitated with $250 \mu 1$ of saturated ammonium sulfate. Samples were centrifuged for 10 minutes at 2,800 RPM (room temperature), and the supernatant containing the unbound corticosterone was decanted into a scintillation vial with $10 \mathrm{ml}$ of a toluene-based cocktail containing $4.0 \mathrm{~g}$ PPO and $0.1 \mathrm{~g}$ bis-MSB per 1 . The pellets containing the precipitated antibody were discarded.

The unbound ${ }^{3} \mathrm{H}$-corticosterone was allowed to partition into the toluene phase overnight, and was read the next morning on a Packard Tri-Carb \#2425 scintillation counter. The data were subjected to log-logit transformations. Unknowns were calculated from the standards using least squares linear regression. Each assay included a quality control sample from a serum pool containing approximately $32.5 \mathrm{\mu g}$ of corticosterone per $100 \mathrm{~m} 1$. The interassay coefficient of variation calculated from these samples was $15.8 \%$.

Glucose analysis. Serum glucose was analyzed by the glucose oxidase method using kit \#510A purchased from Sigma Co. In this procedure, a solution containing horseradish peroxidase and glucose oxidase was added to diluted aliquots of serum. Glucose oxidase 
was used to convert glucose to gluconic acid, yielding hydrogen peroxide as a by product. The horseradish peroxidase and a color reagent, o-dianisidine dihydrochloride were then allowed to react with the peroxide fur 30 minutes at $37^{\circ} \mathrm{C}$, yielding a brown product, oxidized o-dianisidine. The intensity of the brown color as measured at $450 \mathrm{~nm}$ on a Bausch and Lomb \#88 spectrophotometer was proportional to the original glucose concentration. A stock solution of $100 \mathrm{mg} / \mathrm{dl}$ beta-D-glucose in $0.1 \%$ benzoic acid was provided with the kit and stored at $4^{\circ} \mathrm{C}$. Standards of $50-$ $300 \mathrm{mg} / \mathrm{dl}$ were diluted in deionized water for use in the first of these assays and standards of $50-100 \mathrm{mg} / \mathrm{dl}$ were used in each subsequent assay. Unknowns were calculated from the standards using linear regression:

Data analysis. All data were subjected to analyses of variance (ANOVA) followed by individual mean comparisons using Fischer's Least Significant Difference Test (Kirk, 1968). Data from the turnover study were Evaluated using a Student's t-test. Results occuring with a chance probability of less than .05 were considered statistically significant. 
Experiment I. The effect of differing doses of insulin on serum corticosterone and glucose concentrations is shown in Fig. 1. Insulin significantly elevated serum corticosterone $\left(F_{5,25}=28.51\right)$ and lowered glucose levels $\left(F_{5,24}=4.49\right)$ in a dose-dependent manner at all doses except the lowest one, $.125 \mathrm{U} / \mathrm{kg}$. The timecourse of these responses to insulin is shown in Fig. 2. Serum corticosterone reached a maximum at 40 minutes and began to decrease by 60 minutes. Post hoc testing revealed that all groups of insulin treated animals were significantly higher than saline controls $\left(F_{1,40}=64.04\right)$ except at the 20 minute time point. Glucose levels in the insulin treated animals were found to be different than saline controls at all times $\left(F_{1,40}=151.61\right.$; Fig. 3).

Experiment II. The effect of insulin on hypothalamic 5-HT turnover can be seen in Fig. 4. The pargyline induced accumulation of 5-HT 40 minutes following insulin administration was significantly higher than its accumulation following saline $\left(t_{18}=2.67\right)$. This indicates an increased rate of hypothalamic 5-HT synthesis (turnover) as a result of insulin stress. 


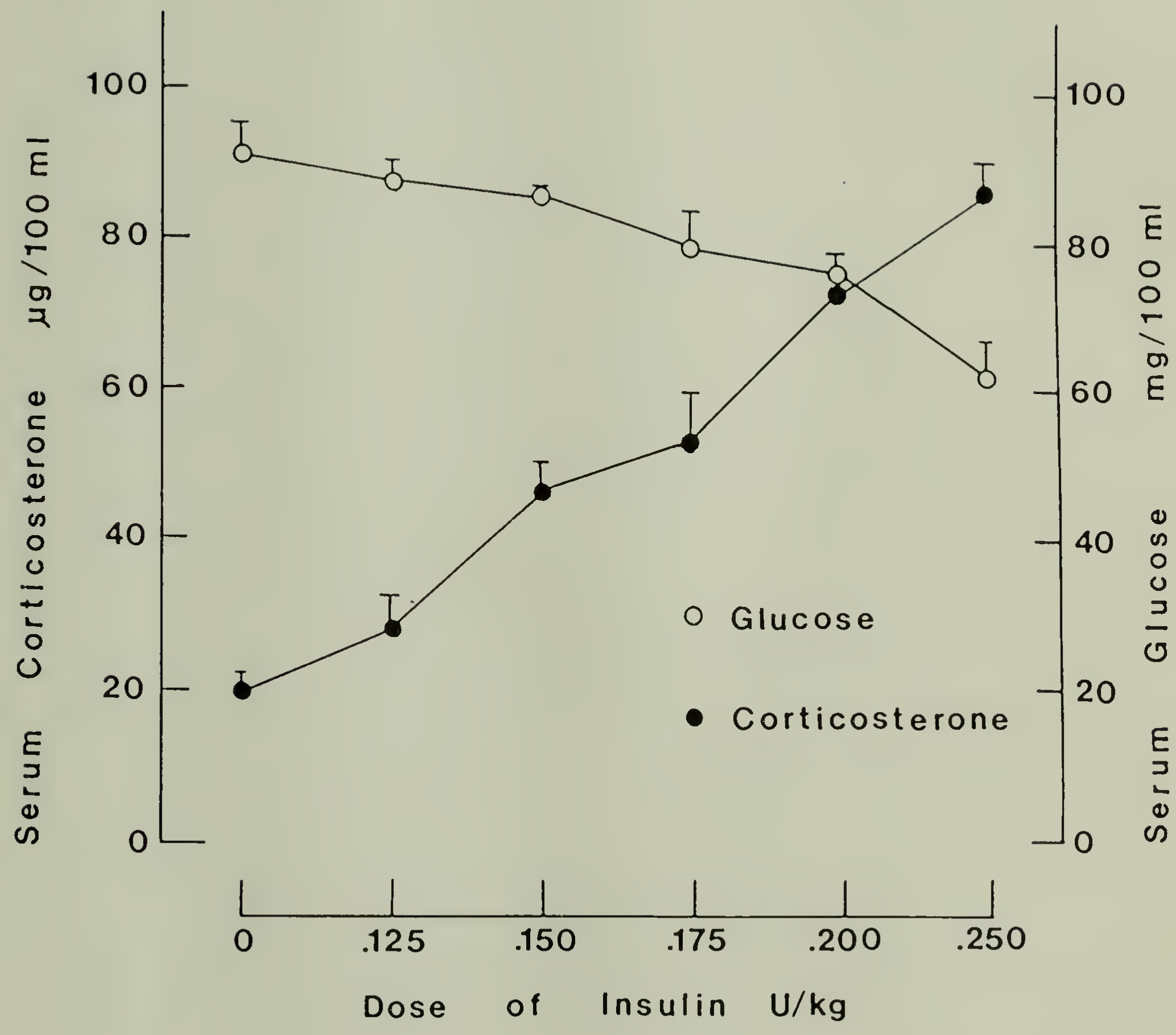

Fig. 1. Dose-dependent changes in serum corticosterone and glucose concentrations following insulin. Insulin was injected s.c. at the doses indicated, $40 \mathrm{~min}$ before the animals were decapitated. Each value shown is the mean \pm SEM for 5 rats per group. 


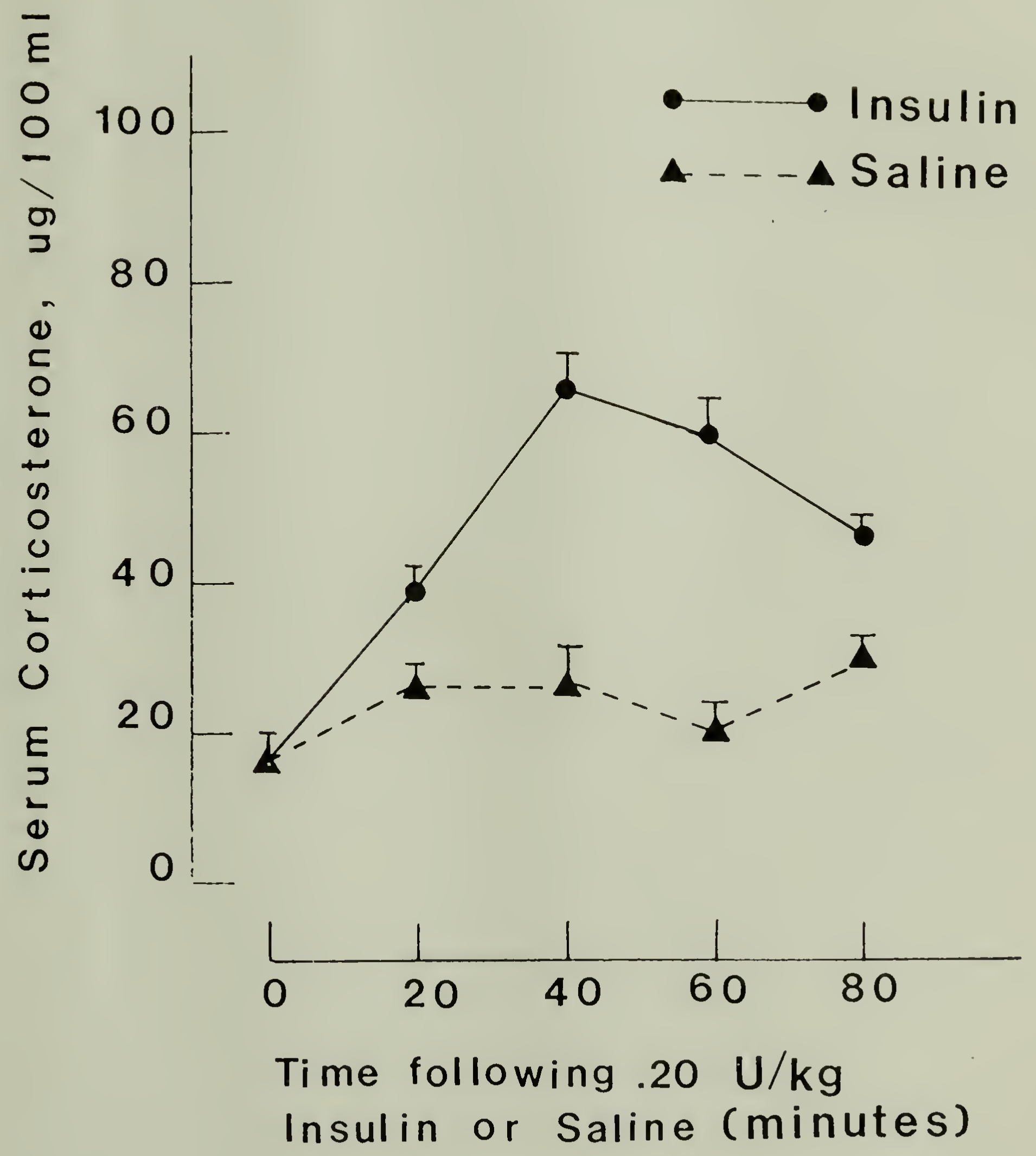

Fig. 2. Time-course effect of insulin on serum corticosterone. $0.20 \mathrm{U} / \mathrm{kg}$ insulin or saline was injected at time zero. Each value shown is the mean \pm SEM for 6 rats per group. 


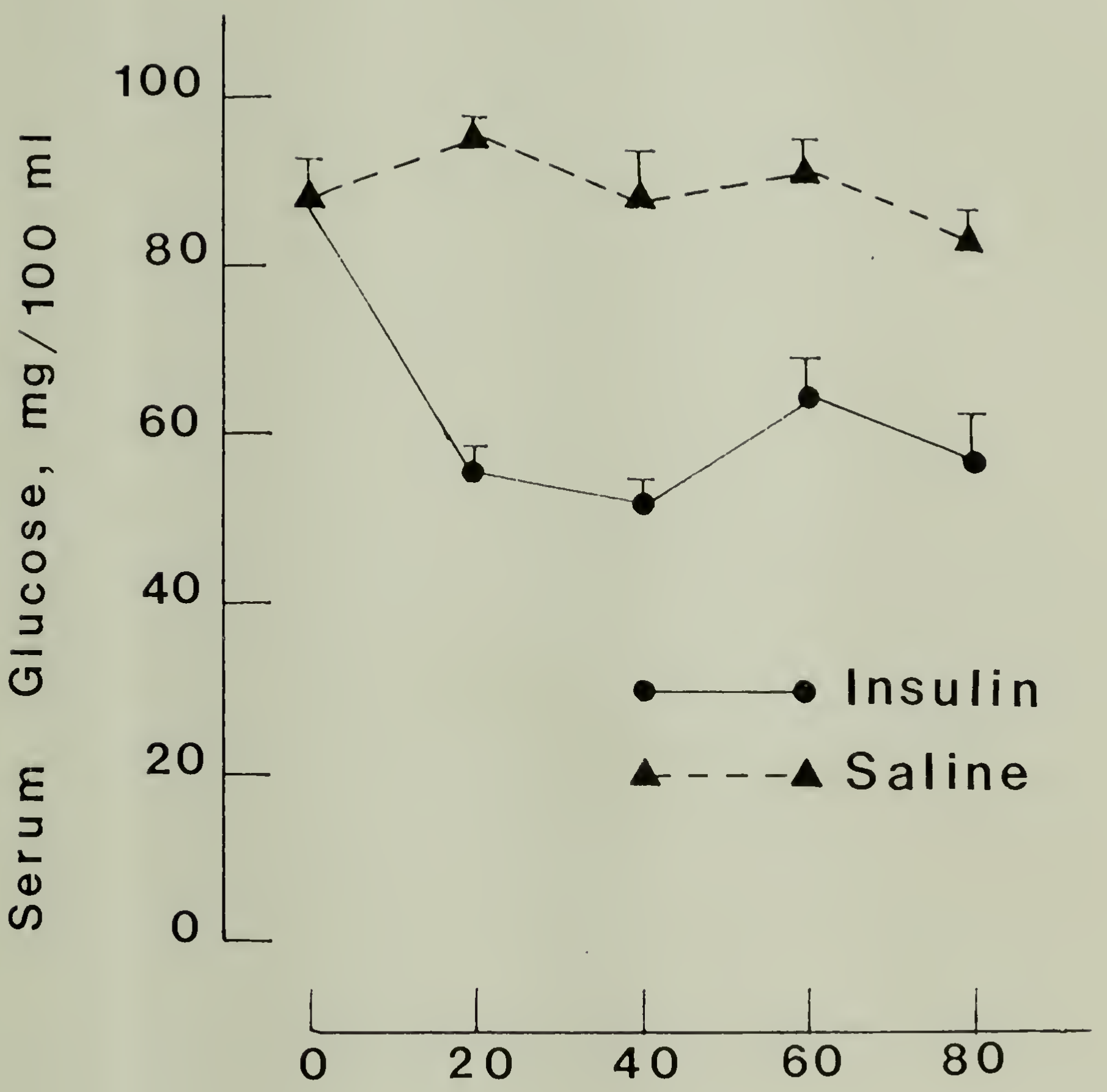

Time following . $20 \mathrm{U} / \mathrm{kg}$ Insulin or Saline (minutes)

Fig. 3. Time-course effect of insulin or serum glucose in the same animals shown in Figure 2. 
Fig. 4. Net hypothalamic accumulation following pargyline. Arimals were injected i.p. with $75 \mathrm{mg} / \mathrm{kg}$ pargyline or saline and then 5 min later either killed, or injected with $0.20 \mathrm{U} / \mathrm{kg}$ insulin or saline. The latter two groups were killed $45 \mathrm{~min}$ after the second injection. Data repwhich the amount of 5-HT above that of the 5 min controls, which had a mean hypothalamic 5-HT conceniration of $0.78 \mu \mathrm{g} / \mathrm{g}$ tissue. Mean hypothalánic weight for all rats was $32.7 \pm 0.1 \mathrm{mg}$. Values represent the mean $\pm \mathrm{SEM}$ for 10 rats per group. 


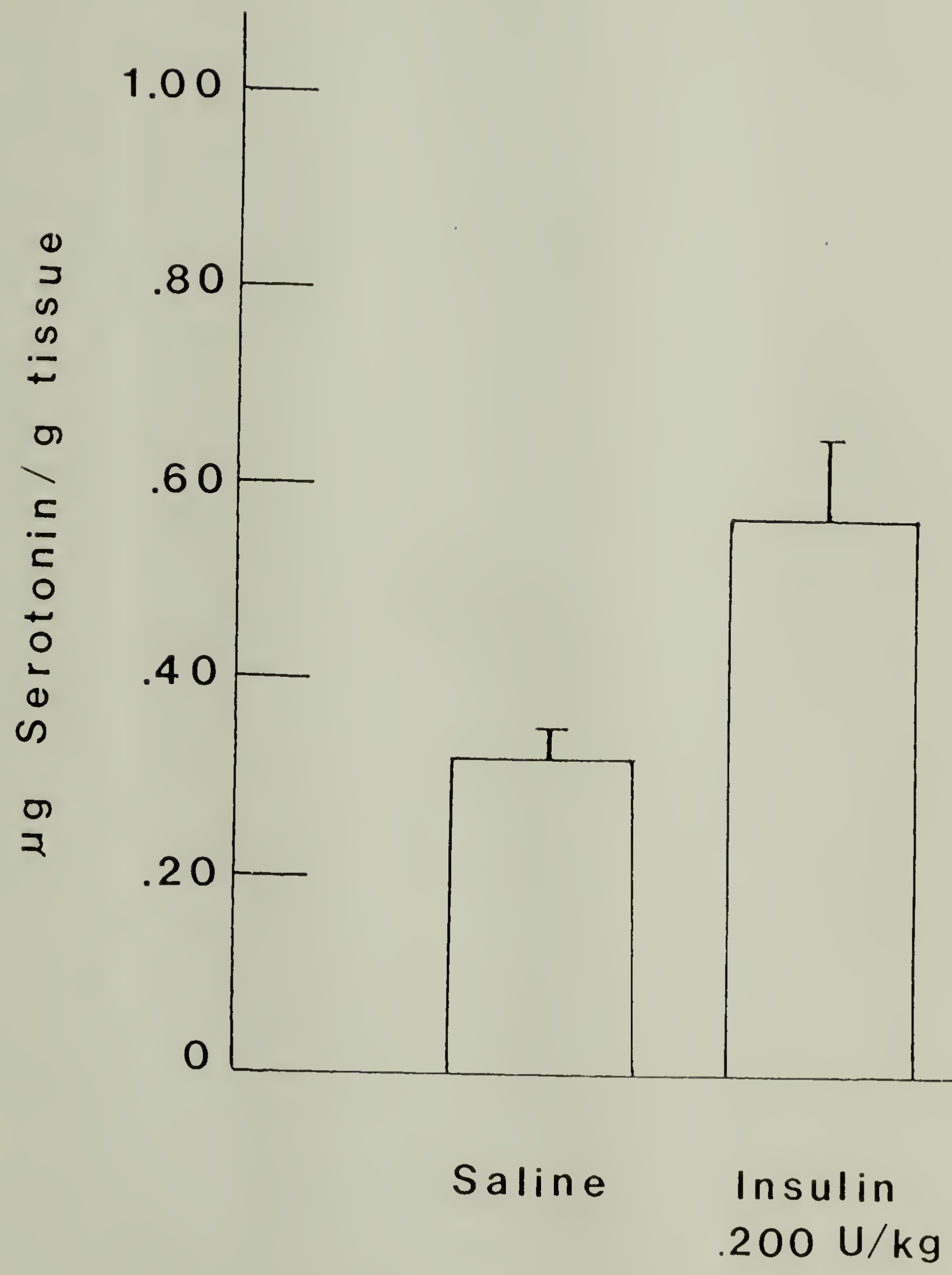

Figure 4 
Experiment III. Altering plasma amino acid concentrations produced substantial changes in the corticosterone response to insulin stress. First, the effect of tryptophan on a submaximal dose of insulin was investigated. An initial ANOVA performed on the data yielded significant main effects for both the treatment $\left(F_{1,32}=13.08\right)$ variables. Rats given $0.150 \mathrm{U} / \mathrm{kg}$ of insulin had higher overall corticosterone levels than their salineinjected counterparts, while tryptophan pretreatment potentiated the responses to both insulin and saline (Fig. 5).

The effect of valine on the corticosterone response to a higher dose of insulin is illustrated in Fig. 6. In this case, an overall ANOVA on the results revealed a significant interaction between treatment with insulin and pretreatment with valine $\left(F_{1,20}=7.70\right)$. It can be seen that although $200 \mathrm{mg} / \mathrm{kg}$ valine did not alter serum corticosterone in saline-injected rats, the same dose almost completely prevented the stress-induced increase in corticosterone observed following insulin. Post hoc testing confirmed that the valine-insulin animals were significantly different from the saline-insulin animals, but did not differ from either control group. These findings are consistent with the idea that tryptophan availability plays an important role in the pituitary adrenal response to insulin-induced hypoglycemia.

Experiment IV. Treatment with methysergide reduced levels of circulating corticosterone in both insulin and saline treated animals $\left(F_{1,27}=7.78\right)$. As illustrated in Fig. 7, the effect of 
Fig. 5. Effect of tryptophan pretreatment on serum corticosterone response to insulin stress. A dose of $0.15 \mathrm{U} / \mathrm{kg}$ insulin or saline was injected s.c. $40 \mathrm{~min}$ before rats were killed and 20 min after the s.c. injection of $200 \mathrm{mg} / \mathrm{kg}$ L-tryptophan. Values represent the mean \pm SEM for 9 rats per group. 


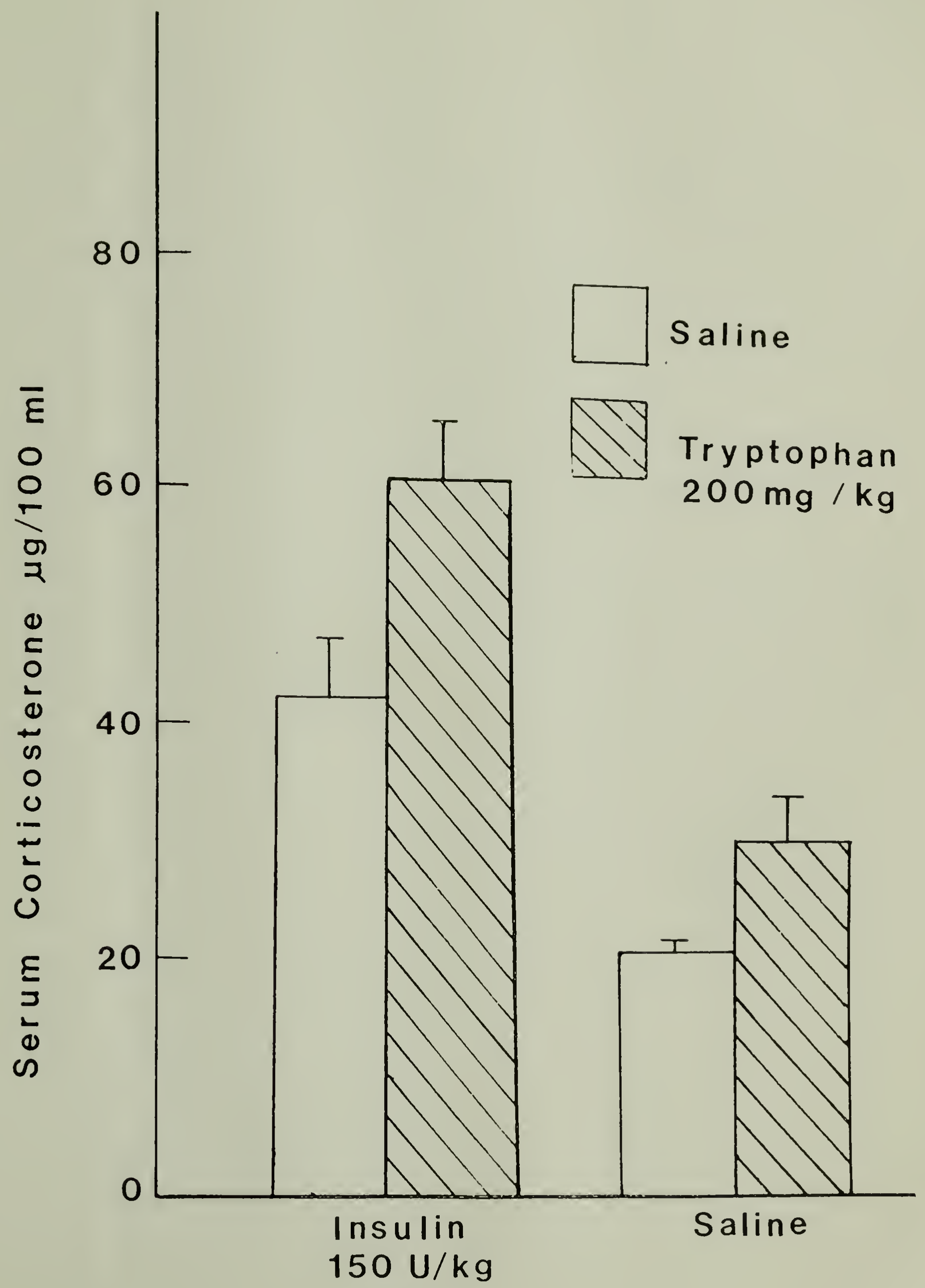

Figure 5 
Fig. 6. Effect of valine pretreatment on serum corticosterone response to insulin stress. A dose of $0.20 \mathrm{U} / \mathrm{kg}$ insulin or saline was injected s.c. 40 min before rats were killed and $20 \mathrm{~min}$ after the s.c. injection of 200 $\mathrm{mg} / \mathrm{kg}$ valine. Values represent the mean \pm SEM for 6 rats per group. 


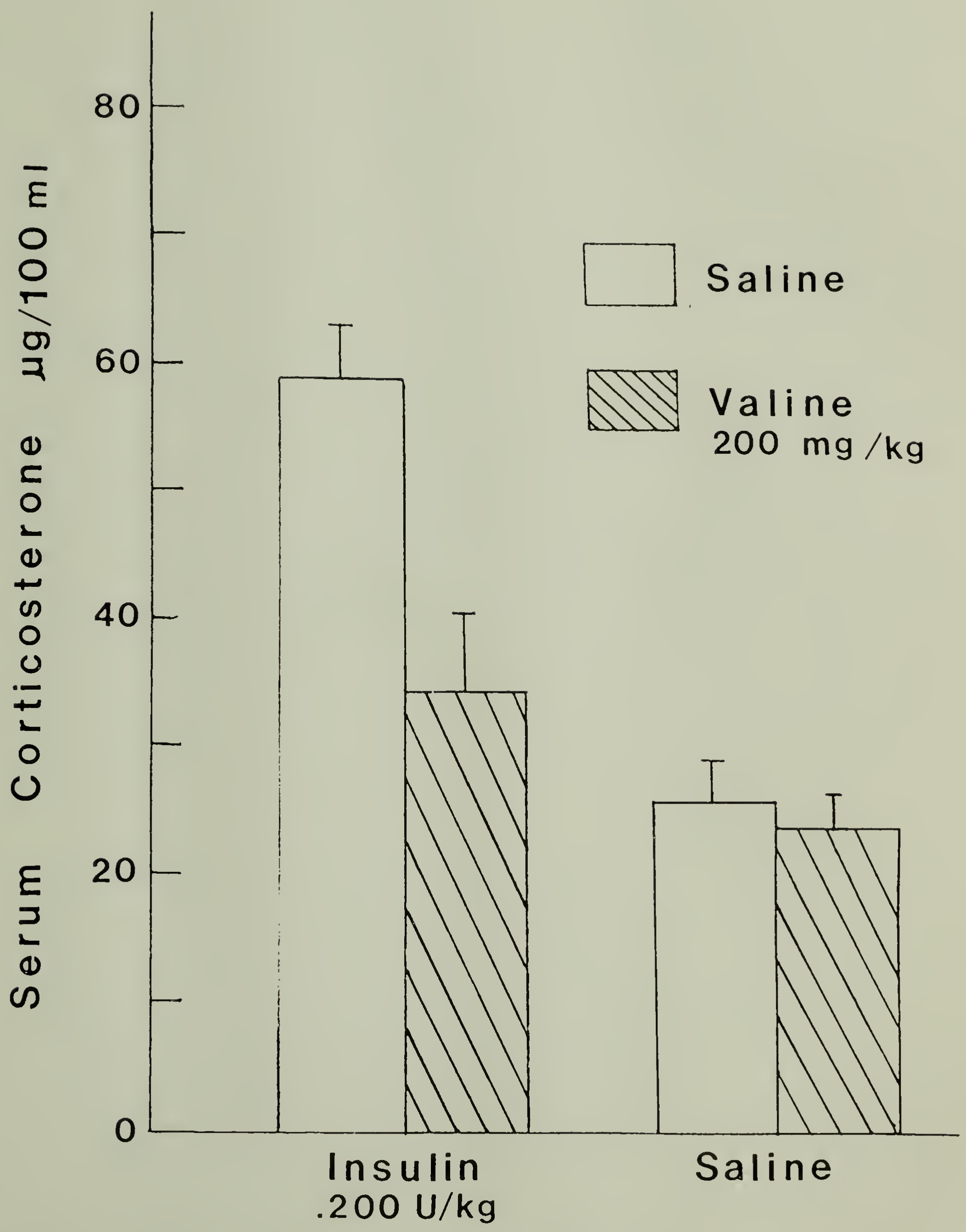

Figure 6 
Fig. 7. Effect of methysergide on the serum corticosterone response to insulin stress. Rats were pretreated with $5 \mathrm{mg} / \mathrm{kg}$ methysergide i.p. $1 \mathrm{~h}$ before receiving $0.20 \mathrm{U} / \mathrm{kg}$ insulin or saline and killed $40 \mathrm{~min}$ later. Values represent the mean \pm SEM for 8 rats in all groups except the methysergide-insulin group, in which $\mathrm{n}=7$. 


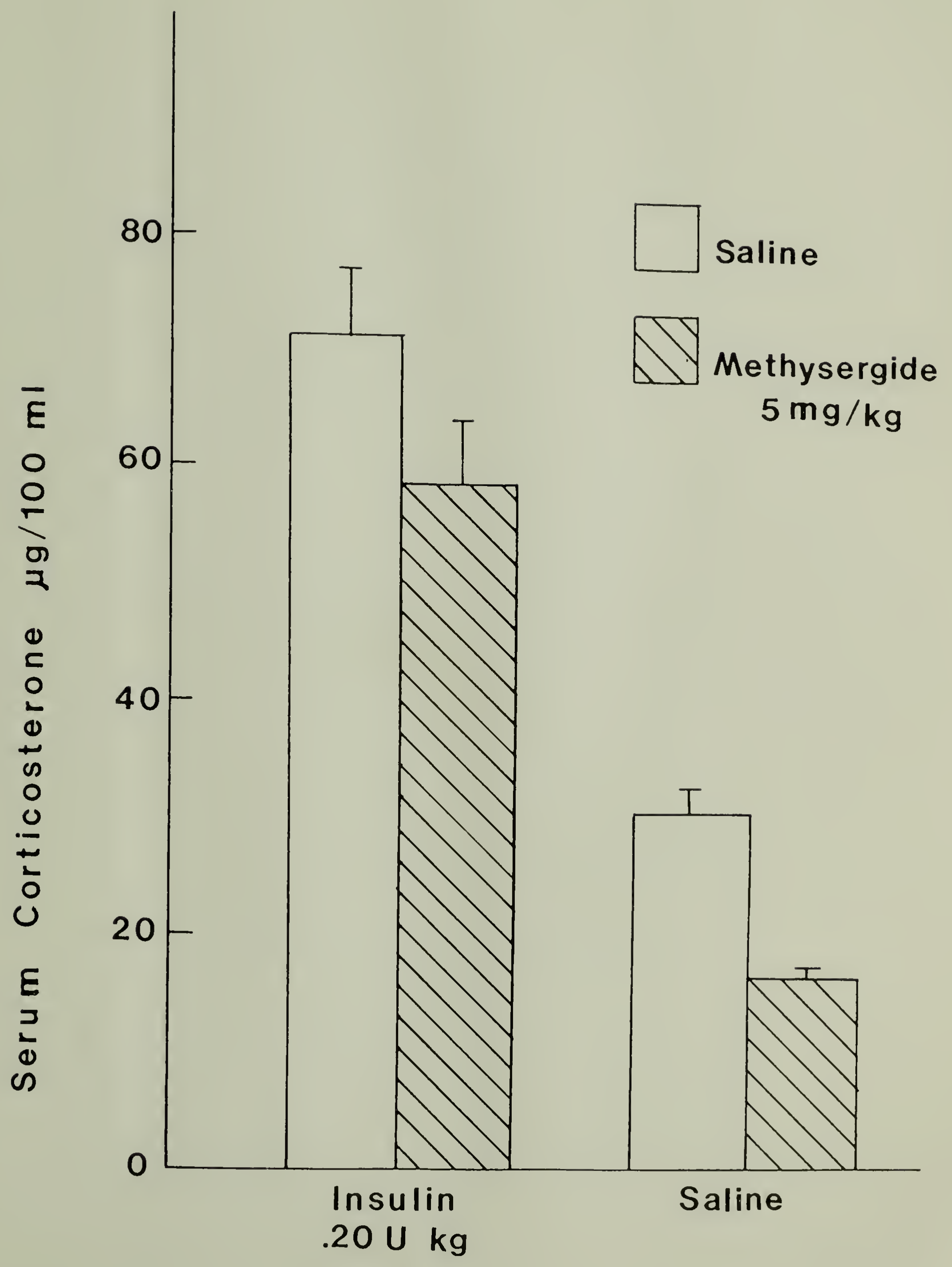

Figure 7 
methysergide was of greater magnitude in the saline-treated controls. It should be noted that these controls have been subjected to two mild stressors, namely i.p. injection and 16 hour food deprivation. Thus, methysergide (at the present dose) was capable of inhibiting pituitary-adrenal responses to stress, but a smaller degree of inhibition was observed when the stress was more potent.

Hypothalamic 5-HT content was depleted by an average of $75 \%$ when measured 10 days after treatment with 5,7-DHT (mean hypothalamic 5-HT content $=0.19 \mu \mathrm{g} / \mathrm{g}$ tissue compared to $0.76 \mu \mathrm{g} / \mathrm{g}$ in sham operated animals) (Fig. 8). Analysis of the corticosterone data revealed a main effect for insulin treatment $\left(F_{1,20}=\right.$ 36.25) and a significant interaction between insulin and 5,7-DHT $\left(F_{1,20}=11.62\right)$. Post hoc testing showed that 5,7-DHT significantly lowered the insulin-induced elevation of serum corticosterone (Fig. 9) 
Fig. 8. Effect of 5,7-DHT on hypothalamic 5-HT content 10 days after the intraventricular injection of $150 \mu \mathrm{g} 5,7-\mathrm{DHT}$ in $0.1 \%$ ascorbic acid or vehicle alone. Values represent the mean \pm SEM for 6 rats per group. 


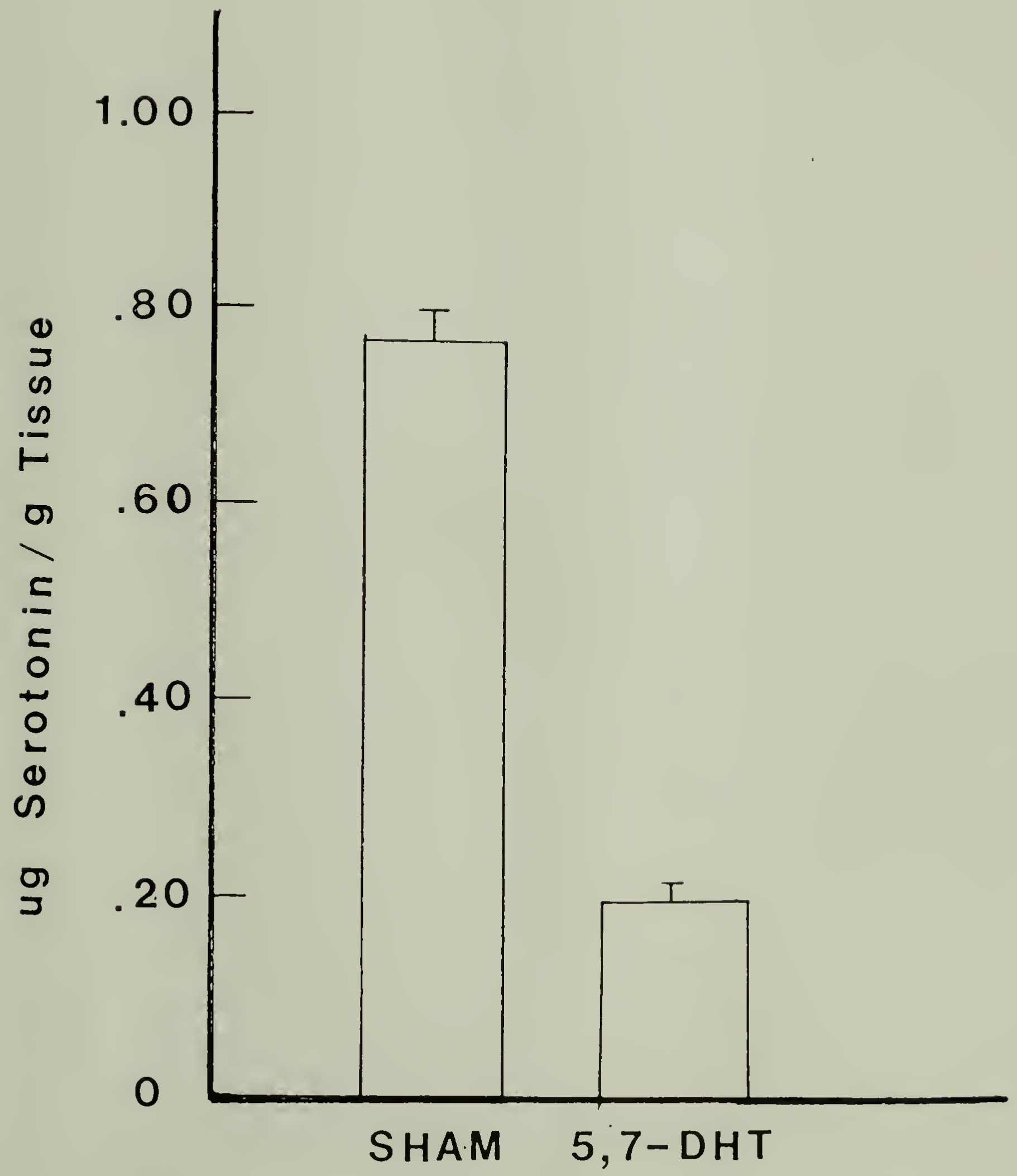

Figure 8 
Fig. 9. Effect of 5,7-DHT on the serum corticosterone response to insulin. $150 \mu \mathrm{g} \mathrm{5,7-DHT}$ in $0.5 \%$ ascorbic acid or vehicle alone was injected intraventricularly 45 min after pretreatment with $25 \mathrm{mg} / \mathrm{kg}$ desipramine.

$0.20 \mathrm{U} / \mathrm{kg}$ insulin or saline were injected 10 days later and the rats killed 40 min following this injection. Values represent the mean \pm SEM for 6 rats per group. 


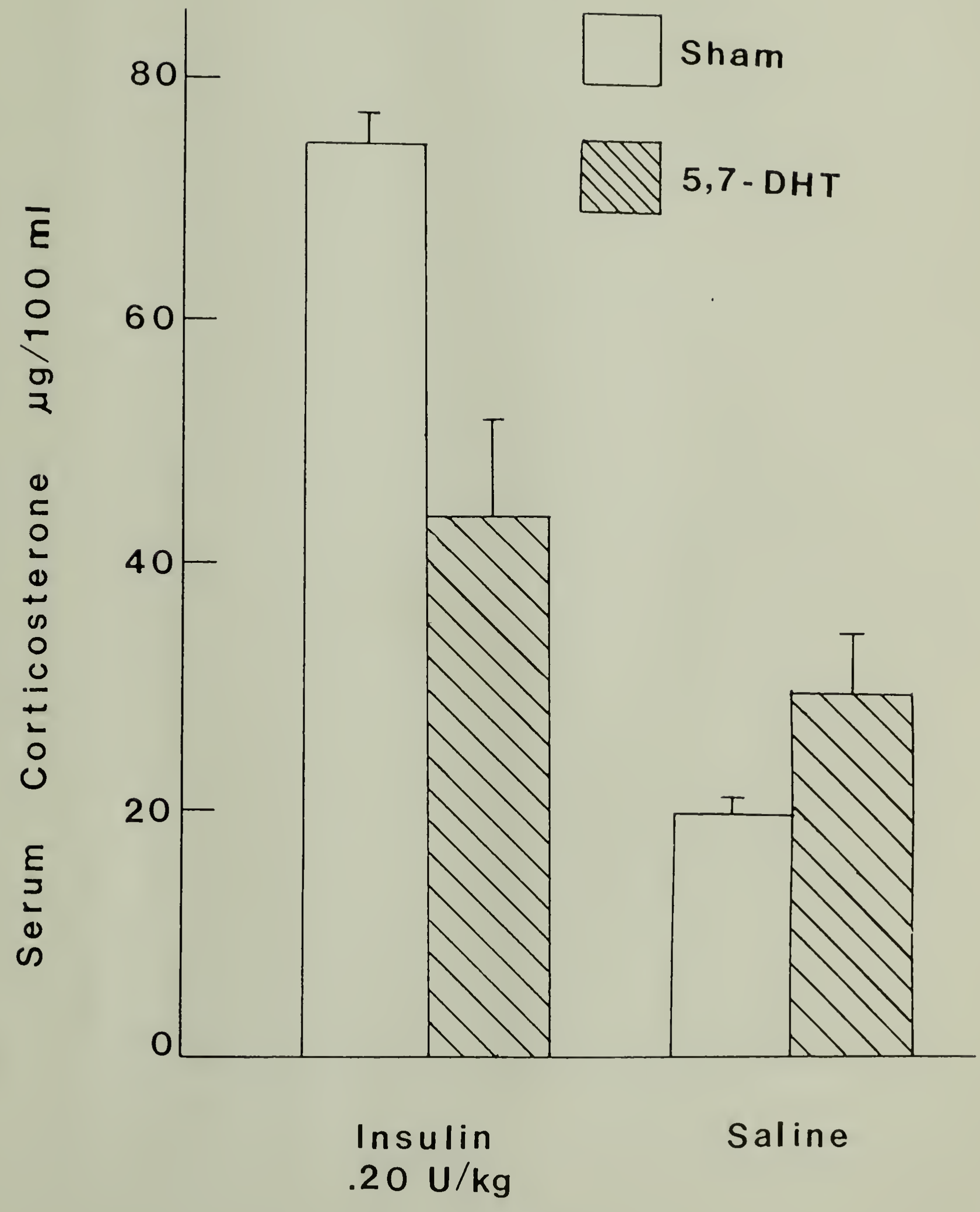

Figure 9 
C H A P T E R I V

\section{DISCUSSION}

The results of these studies support the hypothesis that 5-HT mediates, at least in part, the hypothalamic-pituitary-adrenal response to insulin stress. This conclusion is based on the increase in hypothalamic turnover observed as a result of this stress, and on the ability of the serotonergic manipulations used to appropriately alter these effects.

Tryptophan enhanced the pituitary-adrenal response to insulin while valine reduced it. Using these amino acids as 5-HT manipulations is based on the fact that tryptophan hydroxylase, the rate-1imiting enzyme in 5-HT synthesis is not saturated in brain with its substrate, tryptophan (Friedman, Kappelman, \& Kaufman, 1972). Thus, 5-HT synthesis can be altered by either increasing or decreasing the availability of tryptophan with respect to the enzyme. One of the factors that influence tryptophan availability to the brain is plasma concentrations of large, neutral amino acids which compete with tryptophan for transport across the blood-brain barrier (Pardridge, 1979). Therefore, the amino acid tryptophan was administered so that its concentration and subsequent entrance to the brain would increase. Other animals received valine, which presumably ties up the sites 
on the carrier molecule and therefore reduces the amount of tryptophan entering the brain. The increase in adrenocortical activity seen with tryptophan, and the decrease in response to valine pretreatment suggest that the functional response to insulin was partially related to tryptophan availability.

In addition to plasma amino acid concentrations, there are other factors which affect tryptophan availability to the brain. One such factor appears to be the amount of free vs. total tryptophan in plasma (Knott \& Curzon, 1972). Tryptophan is the only amino acid which is bound to albumin in plasma. Normally, about $80-90 \%$ of total tryptophan is bound while $10-20 \%$ circulates free (McMemory \& Oncley, 1958). Tryptophan shares its binding site with nonesterified fatty acids (NEFA) which can displace tryptiophan and therefore alter the amount of free tryptophan circulating in the blood. If concentrations of NEFA increase, then free tryptophan concentrations also increase. Fasting, for example, increases NEFA, thereby causing increased levels of free tryptophan (Fernstrom, 1979).

It is unclear in which circumstances and to what extent the concentration of free (as opposed to total) tryptophan plays a role in overall tryptophan availability to the brain. For example, Fernstrom and Wurtman (1971) have shown an increase in both 5-HT turnover and brain tryptophan levels in response to insulin. Insulin causes plasma NEFA to be taken up into various peripheral tissues. This liberates albumin binding sites in plasma, and 
therefore increases the proportion of bound to free tryptophan. The idea that free tryptophan concentrations regulate tryptophan availability under these conditions is inconsistent with the increase in brain tryptophan and 5-HT seen by Fernstrom and Wurtman, but this inconsistency can readily be explained when we consider two other factors. First, insulin causes the peripheral uptake of neutral amino acids as well as NEFA. Because tryptophan is bound to albumin, it is not particularly affected in this manner by insulin, and therefore, the concentration of total tryptophan remains unchanged in comparison to the reduced plasma concentration of competing amino acids. The second factor that is important here is the discovery by Yuwiler et al. (1977) that tryptophan has a higher affinity for the brain capillary amino acid transport carrier molecule than it does for albumin. Therefore, tryptophan, whether it is bound or free, can readily be available for entrance to the brain. In light of this, it seems that the most important factor regulating tryptophan availability following insulin is the reduction of plasma amino acids which compete with tryptophan for entrance into the brain. The relative concentrations of free vs. total tryptophan may also be important factors, but they probably play a more significant role in increasing brain tryptophan in the absence of reduced plasma amino acid levels. It is interesting to note that tryptophan also increased the serum corticosterone concentrations in the noninsulin controls. This increase may be due to the fasted state of 
the animals since previous studies (Meyer \& Yehuda, unpublished observations) have found no response to tryptophan alone in nonfasted animals. The results of these experiments are consistent with the idea that tryptophan availability increases in response to insulin due to the uptake of competing amino acids by peripheral tissues. The resultant increase in brain tryptophan enhances 5-HT neurotransmission thereby activating pituitary-adrenocortical secretion.

The pharmacological studies also support a role for 5-HT in the adrenocortical response to stress. Methysergide produced an overall reduction in serum corticosterone concentration observed following both the mild stress of fasting and saline injection and the more severe stress of insulin-induced hypoglycemia. Clearly, the effect of methysergide was more robust in reducing corticosterone responses to the milder stress. The inability of methysergide to show a more substantial attenuation of the response to insulin may be due in part to the great magnitude of the corticosterone response to this stressor.

Alternatively, one could attribute the modest attenuation by methysergide to the action of other neurotransmitters which may be involved in the pituitary-adrenal response to insulin stress. Although this possibility should not be ruled out, the other studies reported above suggest a more significant role for 5-HT. Thus, the weak effect of methysergide in contrast to the efficacy of the other manipulations used here may be due to the particular 
pharmacological actions of this drug. It is known, for example, that methysergide blocks Type 2 but not Type 1 5-HT receptors (Peroutka, Lebovitz \& Snyder, 1981). As discussed in the Introduction, Type 2 receptors mediate post-synaptic excitation by $5-\mathrm{HT}$. The partial inhibition of pituitary-adrenal functioning by methysergide therefore suggests the possible involvement of this specific receptor population.

The effect of methysergide on fasted, saline treated animals is consistent with the idea of increased 5-HT synthesis due to tryptophan availability. In fasted animals there is an increased concentration of free tryptophan due to the displacement of tryptophan from plasma albumin binding sites by NEFA. Since the plasma concentrations of related amino acids remain unaltered, the increase in free tryptophan concentration becomes an important factor in the availability of tryptophan for transport into the brain and subsequent conversion to 5-HT. Thus, the effect of methysergide on serum corticosterone following fasting and saline administration suggests that 5 -HT mediates the pituitary-adrenal response to this stressor as well.

It was important that the insulin treated animals have comparable blood glucose levels to ensure a consistent corticosterone response to the treatment. Thus, it was necessary to also impose this mild stress of fasting in the control group. Because of this, the corticosterone levels in the control animals do not represent baseline values, and therefore it is 
difficult to interpret the effects of pharmacological manipulations that altered serum corticosterone concentrations in this group. In an ideal situation, these drugs should additionally be tested on nonfasted subjects to discern whether they would also affect baseline levels in unstressed animals.

Treatment with 5,7-DHT significantly reduced the pituitaryadrenal response to insulin, despite causing slightly increased levels of circulating corticosterone in the saline-treated controls. This latter result could be due to a nonspecific malaise or weight loss produced by 5,7-DHT rather than its direct antiserotonergic activity in pituitary-adrenal functioning. The effectiveness of 5,7-DHT in lowering corticosterone responses to insulin stress suggests that this process is centrally mediated. The specific pathways involved in stimulating pituitary-adrenal function in response to insulin stress, however are not yet known. The dorsal and medial raphe nuclei which are rich in 5-HT containing cell bodies have been shown to ascend to the hypothalamus and therefore, are likely candidates for mediating 5-HT induced changes in $\mathrm{CRH}$ secretion. General evidence for an involvement of extrahypothalamic pathways is provided in a study by Karteszi et al. (1982) who reported that anterolateral deafferentation of the hypothalamus greatly reduced the corticosterone rise seen in response to insulin. In contrast, however, Aizawa, Yasuda and Greer (1981) have shown that complete hypothalamic isolation did not prevent the corticosterone 
response to insulin. The latter finding would be more consistent with a possible involvement of serotonergic neurons within the hypothalamus itself (Kent \& Sladek, 1981). Evidence for the existence of 5-HT nerve terminals in the hypothalamus which stimulates $\mathrm{CRH}$ release have already been clearly demonstrated in the in vitro studies mentioned in the Introduction. Therefore, it is possible that these recently discovered 5-HT neurons within the hypothalamus may act to mediate pituitary-adrenal activity. More studies will be needed to resolve this issue.

Although questions still remain the present research demonstrates a serotonergic mediation of the pituitary-adrenal response to insulin stress which most likely depends on increased tryptophan availability. Other studies have similarly shown a correlation between pituitary-adrenal stimulation and increased brain tryptophan in response to immobilization stress (Curzon, Joseph \& Knott, 1973; Mueller et al., 1976; Kenneth \& Joseph, 1981). These studies showed comparable endocrine responses to tryptophan administration and immobilization, and in one case demonstrated that valine pretreatment reduced both the brain tryptophan and adrenocortical effects following immobilization (Kenneth \& Joseph, 1981). In other experiments, restraint stress (Knott, Joseph \& Curzon, 1973) and novelty stress (Knott, Hutson \& Curzon, 1977) were associated with increased plasma levels of NEFA, suggesting that the increase in brain tryptophan seen in response to these stressors may reflect an increased availability 
of free tryptophan. Thus, changes in brain 5-HT mediated by altered tryptophan availability may be important in the pituitary-adrenal response to a variety of stressors. 


\section{BIBLIOGRAPHY}

Aghajanian, G. K. The modulatory role of serotonin at multiple receptors in brain. In B. I. Jacobs \& A. Gelperin (Eds.) Serotonin, Neurotransmission and Behavior, Cambridge: MIT Press, 1981.

Aizawa, T., Yasuda, N. \& Greer, M. A. Hypoglycemia stimulates ACTH secretion through a direct effect on the basal hypothalamus. Metabolism, 1981, 30, 996-1000.

Balestreri, R., Bertolini, S. \& Castello, C. The Neural Regulation of ACTH secretion in man. In A. Polleri \& R. M. Macleod (Eds.) Neuroendocrinology: Biological and Clinical Aspects, New York: Academic Press, 1979.

Baumgarten, H. G., Bjorklund, A., Nobin, A., Rosengren, E. \& Schlossberger, H. G. Neurotoxicity of hydroxylated tryptamines: structure-activity relationships. Acta Physiological Scandavica, 1975, Supplementum 429, 7-27.

Beaudet, A. \& Descarries, L. Radioautograhpic characterization of a serotonin accumulating nerve cell group in adult rat hypothalamus. Brain Research, 1979, 160, 331-343.

Bjorklund, A., Baumgarten, H. . \& Rensch, A. 5,7-DHT: Improvement of its selectivity for serotonin neurons in the CNS by pretreatment with desipramine. Journal of Neurochemistry, $1975, \underline{24}, 833-835$. 
Bliss, E. L., Thatcher, W. \& Ailion, J. Relationship of stress to brain serotonin and 5-hydroxyindoleacetic acid. Journal of Psychiatric Research, 1972, 9, 71-80.

Bloom, F. E., Battenberg, E. L. F., Rivier, J. \& Vale, W. Corticotropin releasing factor (CRF): Immunoreactive neurons and fibers in rat hypothalamus. Regulatory Peptides, 1982, 4, $43-48$.

Buckingham, C. \& Hodges, J. R. Hypothalamic receptors influencing the secretion of corticotrophin releasing hormone in the rat. Journal of Physiology, 1979, 290, 421-431.

Cavagnini, F., Raggi, V., Micossi, P., DiLandro, A. \& Invitti, C. Effect of an antiserotonergic drug, metergoline, on the ACTH and cortisol responses to insulin hypoglycemia and Iysine-vasopressin in man. Journal of Clinical Endocrinology and Metabolism, 1976, 43, 306-312.

Curzon, G., Joseph, M. \& Knott, P. J. Effects of immobilization and food deprivation on rat brain tryptophan metabolism. Journal of Neurochemistry, $1972,19,1967-1974$.

Dallman, M. F., Engeland, W. C. \& Shinsako, J. Nytohemeral rhythm in adrenal responsiveness to ACTH. Proceedings of the 58th Annual Meeting of the Endocrine Society, 1976, 58 .

De Schaepdryver, A., Preziosi, P. \& Scapagnini, U. Brain monoamines and adrenocortical activation. British Journal of Pharmacology, $1969,35,460-467$. 
Fernstrom, J. D. Diet-induced changes in plasma amino acid pattern: Effects on the brain uptake of large, neutral amino acids, and on brain serotonin synthesis. Journal of Neura1 Transmission, 1979, Supplementum 15, 55-67.

Fernstrom, J. D. Physiological control of brain serotonin synthesis: Relevance to physiology and behavior. In B. I. Jacobs \& A. Gelperin (Eds.) Serotonin, Neurotrans$\underline{\text { mission }}$ and Behavior, Cambridge: MIT Press, 1981.

Fernstrom, J. D. \& Wurtman, R. J. Brain serotonin content: increase following ingestion of carbohydrate diet. Science, $1971,174,1023-1025$.

Friedman, P. A., Kappelman, A. H. \& Kaufman, S. Partial purification and characterization of tryptophan hydroxylase from rabbit hindbrain. Journal of Biological Chemistry, $1972,247,4165-4173$.

Fuller, R. W. Serotonergic stimulation of pituitary-adrenocortical function in rats. Neuroendocrinology, 1981, 32, 118127.

Fuller, R. W. \& Clemens, J. A. Role of serotonin in the hypothalamic regulation of pituitary function. In B. Haber, S. Gabay, M. R. Issidorides, \& S. G. A. Alivisatos (Eds.)

Serotonin: Current Aspects of Neurochemistry and Function. New York: Plenum Press, 1981. 
Fuller, R. W. \& Snoddy, H. D. Elevation of plasma corticosterone by swim stress and insulin-induced hypoglycemia in control and fluoxetine-pretreated rats. Endocrine Research Communications, 1977,4 , 11-23.

Fuller, R. W. \& Snoddy, H. D. The effects of metergoline and other serotonin receptor antagonists on serum corticosterone concentration in rats. Endocrinology, 1979, 105, 923-928.

Fuller, R. W. \& Snoddy, H. D. Effects of serotonin-releasing drugs on serum corticosterone concentration in rats. Neuroendocrinology, $1980,31,96-100$.

Fuller, R. W. \& Snoddy, H. D. Elevation of serum corticosterone concentrations in rats by pergolide and other dopamine agonists. Endocrinology, 1981, 109, 1026-1032.

Fuller, R. W., Snoddy, H. D. \& Clemens, J. A. The effect of quipazine, a serotonin receptor agonist, on serum corticosterone concentration in rats. Endocrine Research Communications, $1978, \underline{5}, 161-171$.

Fuller, R. W., Snoddy, H. D. \& Molloy, B.B. Pharmacologic evidence for a serotonin neural pathway involved in hypothalamic-pituitary-adrenal function in rats. Life Sciences, $1976, \underline{19}, 337-346$.

Hillhouse, E. W., Burden, J. L. \& Jones, M. T. The effect of various putative neurotransmitters on the release of corticotrophin-releasing hormone from the hypothalamus of the rat in vitro. (1) The effect of acetylcholine and noradrenaline. 
Neuroendocrinology, 1975, 17, 1-11.

Holman, R. B., Angwin, P.\& Barchas, J. D. Simultaneous deter-mination of indole- and catecholamines in small brain regions in the rat using a weak cation exchange resin. Neuroscience, $1970,1,147-150$.

Holmes, M. C., DiRenzo, G., Gillham, B.\& Jones, M. T. Role of serotonin in the control of secretion of corticotrophin releasing factor. Journal of Endocrinology, 1982, 93, $151-160$.

Imura, H., Nakai, Y. \& Yashimi, T. Effect of 5-hydroxytryptophan (5-HTP) on growth hormone and ACTH release in man. Journal of Clinical Endocrinology and Metabolism, 1973, 36, 204-206.

Jacobowitz, D.M. \& Richardson, J. S. Method for the rapid determination of norepinephrine, dopamine, and serotonin in the same brain region. Pharmacology, Biochemistry, and Behavior, $1978,8,515-519$.

Jones, M. T., Hillhouse, E. W. \& Burden, J. Effect of various putative neurotransmitters on the secretion of corticotrophin-releasing hormone from the rat hypothalamus in vitro; a model of the neurotransmitters involved. Journal of Endocrinology, $1976,69,1-10$.

Karteszi, M., Dallman, M.F., Makara, G.B.\& Stark, E. Regulation of the adrenocortical response to insulin induced hypoglycemia. Endocrinology, 1982, 111, 535-541. 
Karteszi, M., Palkovitz, M., Kiss, J. Z., Kanyicska, B., Fekete, M. I. K. \& Stark, E. Lack of correlation between hypothalamic serotonin and the ether-induced ACTH secretion in adrenalectomized rats. Neuroendocrinology, 1981, 32, 7-13.

Kennett, G. A. \& Joseph, M. H. The functional response to restraint stress. Neuropharmacology, 1981, 20, 39-43.

Kent, D. L. \& Sladek, J. R. Histochemical, pharmacological and microspectrofluorometric analysis of new sites of serotonin localization in the rat hypothalamus. Journal of Comparative Neurology, 1978, 180, 221-236.

Kirk, R. E. Experimental design: Procedures for the behavioral sciences. Belmont: Brooks/Cole, 1968.

Knott, P. J. \& Curzon, G. Free tryptophan in plasma and brain tryptophan metabolism. Nature, 1972, 239, 452-453.

Knott, P. J., Hutson, P. H. \& Curzon, G. Fatty acid and tryptophan changes on disturbing groups of rats and caging them singly. Pharmacology, Biochemistry and Behavior, 1977, $\underline{7}$, $245-252$

Knott, P. J., Joseph, M. H. \& Curzon, G. Effect of food deprivation and immobilization on tryptophan and other amino acids in rat brain. Journal of Neurochemistry, 1973, 20, 249-251.

Krieger, D. T. Serotonin and regulation of ACTH secretion. In D. T. Krieger \& W. F. Ganong (Eds.) ACTH and Related Peptides: Structure, Regulation and Action. Annals of New York Academy of Science, $1977, \underline{297}, 527-534$. 
Krieger, D. T., Amorosa, L. \& Linick, F. Cyproheptadine-induced remission of Cushing's disease. New England Journal of Medicine, $1975,293,893-896$.

Krieger, D. T. \& Luria, M. Effectiveness of cyproheptadine in decreasing plasma ACTH concentrations in Nelson's syndrome. Journal of Clinical Endocrinology and Metabolism, 1976, 43, 1179-1182.

Krieger, H. P. \& Krieger, D. T. Chemical stimulation of the brain: effect on adrenal corticoid release. American Journal of Physiology, 1970, 218, 1632-1641.

Maikel, R. P.\& Miller, F. P. Fluoroescent products formed by reaction of indole derivatives and o-pthalaldehyde. Analytical Chemistry, 1966, 38, 1937-1938.

Marotta, S. F., Sithichoke, N., Garcy, A. M. \& Yu, M. Adrenocortical responses of rats to acute hypoxic and hypercapnic stresses after treatment with aminergic agents. Neuroendocrinology, 1976, 20, 182-192.

McMenamy, R. N. \& Oncley, J. L. The specific binding of Ltryptophan to serum albumin. Journal of Biological Chemistry, $1958,223,1436-1447$.

Meyer, J. S., Buckholtz, N. S. \& Boggan, W. O. Serotonergic stimulation of pituitary-adrenal activity in the mouse. Neuroendocrinology, $1978,26,312-324$. 
Meyer, J. S., McElroy, J.F., Yehuda, R.\& Miller, J. Serotonergic stimulation of pituitary-adrenocortical activity: evidence for multiple sites of action. submitted for publication, 1983.

Moore, R. Y. The anatomy of central serotonin neuron systems in the rat brain. In B. I. Jacobs \& A. Gelperin (Eds.)

Serotonin, Neurotransmission and Behavior, Cambridge: MIT Press, 1981

Morgan, W. W., Rudeen, P. K. \& Pfeil, K. A. Effect of immobilization stress on serotonin content and turnover in regions of the rat brain. Life Science, 1975, 17, 143-150.

Mueller, G. P., Twohy, C. P., Chen, H. T., Advis, J. P.\& Meites, J. Effects of L-tryptophan and restraint stress on hypothalamic and brain serotonin turnover and pituitary TSH and prolactin release in rats. Life Science, 1976, 18, $715-724$.

Murphy, B. E. \& Diez D'Aux, R.C. The use of sephadex LH-20 column chromotography to separate unconjugated steroids. Journal of Steroid Biochemistry, 1975, 6, 233-237.

Naumenko, E. V. Effect of local injection of 5-hydroxytryptamine into rhinencephalic and mesencephalic structures on pituitary adrenal function in guinea-pigs. Neuroendocrinology, 1969, 5, 81-88.

Naumenko, E. V. Hypothalamic chemoreactive structures and the regulation of pituitary-adrenal function. Effects of local injections of norepinephrine, carbachol and serotonin into 
the brain of guinea pigs with intact brains and after mesencephalic transection. Brain Research, 1968, 11, 1-10.

Neff, N. H. \& Tozer, T. N. In vivo measurement of brain 5-HT

turnover. Advances in Pharmacology, 1968, 6A, 97-109.

Pardridge, W. M. The role of blood-brain barrier transport of

tryptophan and other neutral amino acids in the regulation of substrate-limited pathways of brain amino acid metabolism.

Journal of Neurai Transmission, 1979, Supplementum 15, 43-54.

Peroutka, S. J., Lebovitz, R. M. \& Snyder, S. H. Two distinct central serotonin receptors with different physiological functions. Science, $1981, \underline{212}, 827-829$.

Peroutka, S. J. \& Snyder, S. H. Multiple serotonin receptors: differential binảings of ${ }^{3} \mathrm{H}$ 5-hyàroxytryptamine, ${ }^{3} \mathrm{H}$ lysergic acid diethylamine and ${ }^{3} \mathrm{H}$ spiroperidol. Molecular Pharmacology, 1979, 16, 687-699.

Plonk, J. \& Feldman, J. M. Modification of adrenal function by the antiserotonin agent cyproheptadine. Journal of Clinical Endocrinology and Metabolism, 1976, 42, 291-295.

Popova, N. K., Maslova, L. N. \& Naumenko, E. V. Serotonin and the regulation of the pituitary-adrenal system after deafferentation of the nypothalamus. Brain Research, 1972, 47, 61-67. 
Roberts, M. H. T. \& Straughan, D. W. Excitation and depression of cortical neurons by 5-hydroxytryptamine. Journal of Physiology (London), 1967, 193, 269-294.

Koth, K. A., Mefford, I. M. \& Barchas, J. D. Epinephrine, norepinephrine, dopamine and serotonin: differential effects of acure and chronic stress on regional brain amines. Brain Research, 1982, 239, 417-424.

Scapagnini, U., Van Loon, G. R., Moberg, G. P., Preziosi, P.\& Ganong, W. F. Evidence for central norepinephrine mediated inhibition of ACTH secretion in the rat. Neuroendocrinology, $1972,10,155-160$

Steiner, J. A. \& Grahame-Smith, D. G. Pharmacological control of corticosterone secretion in the intact rat. British Journal of Pharmacology, $1979,67,489 \mathrm{P}-490 \mathrm{P}$.

Telegdy, G. \& Vermes, I. Changes induced by stress in the activity of the serotonergic system in limbic brain structures. In E. Usdin, R. Kvetnansky, \& I. Kopin (Eds.) Catecholamines and Stress, Oxford: Pergamon Press LTD., 1976. Tozer, T. N., Neff, N. H. \& Brodie, B. B. Application of steady state kinetics to the synthesis rate and turnover time of serotonin in the brain of normal and reserpine treated rats. Journal of Pharmacology and Experimental Therapeutics, 1966, $153,177-182$. 
Vale, W., Speiss, J., Rivier, C. \& Rivier, J. Characterization of a 41-residue ovine hypothalamic peptide that stimulates secretion of corticotropin and B-endorphin, Science, 1981, $\underline{213}, 1394-1397$.

Van Loon, G. R., Scapagnini, U., Cohen, R. \& Ganong, W. F. Effect of intraventricular administration of adrenergic drugs on the adrenal venous 17-hydroxycorticosteroid response to surgical stress in the dog. Neuroendocrinology, 1971 (a), 8, $257-272$.

Van Loon, G. R., Scapagnini, U., Moberg, G. \& Ganong, W. F. Evidence for central adrenergic neural inhibition of ACTH secretion in rats. Endocrinology, 1971 (b), 89, 1464-1469.

Vermes, I., Dull, G., Telegdy, G. \& Lissak, K. Possible role of serotonin in the monoamine-induced inhibition of the stress mechanism of the rat. Acta Physiologica Academiae Scientiarum Hungaricae, $1972,42,219-233$.

Vermes, I. \& Telegdy, G. Effect of intraventricular injection and intrahypothalamic implantation of serotonin on the hypothalamo-hypophyseal-adrenal system in the rat. Acta Physiologica Academiae Scientiarum Hungaricae, 1972, 42, 49-59.

Vernikos-Danellis, J. \& Berger, P. A. Brain serotonin and the pituitary-adrenal system. In J. Barchas \& E. Usdin (Eds.) Seroconin and Behavior, New York: Academic Press, 1973. 
Vernikos-Danellis, J. \& Fieyback, J. P. Psychophysiologic mechanisms regulating the hypothalamic-pituitary-adrenal response to stress. In H. Selye (Ed.) Selye's Guide to Stress Research, New York: Van Nostrand Reinhold Company, 1980.

Wilcox, C. J., Aminoff, M. J., Millar, J. G. A., Keenan, J.\& Kremer, M. Circulating levels of corticotrophin and cortisol after infusions of L-dopa, dopamine and noreadrenaline in man. Clinical Endocrinology, 1975, 4, 191-198.

Woolf, P. D. \& Lee, L. Effect of the serotonin precursor, tryptophan, on pituitary hormone secretion. Journal of Clinical Endocrinology and Metabolism, 1977, 45, 123-133. Yuwiler, A., Oldendorf, W. H., Geller, E. \& Braun, L. Effect of albumin binding and amino acid competition on tryptophan uptake into brain. Journal of Neurochemistry, 1977, 28, 1015-1023. 
H

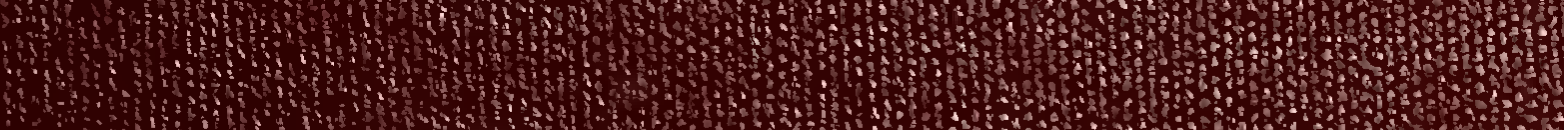
(1) 1 (1) (n) (1) (1) (1) (1) (

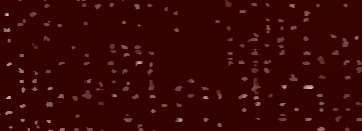

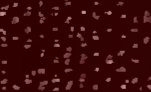

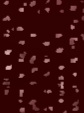

40

13

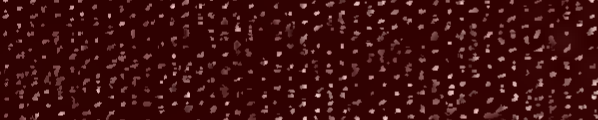

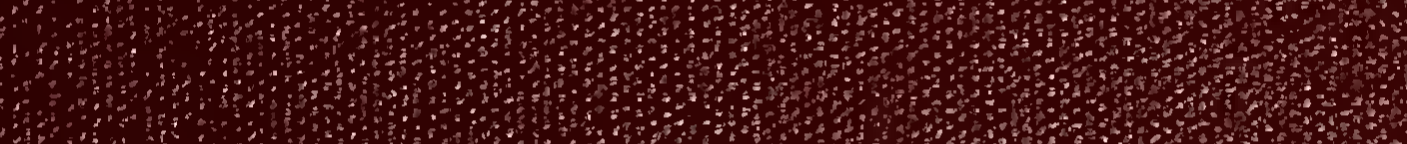

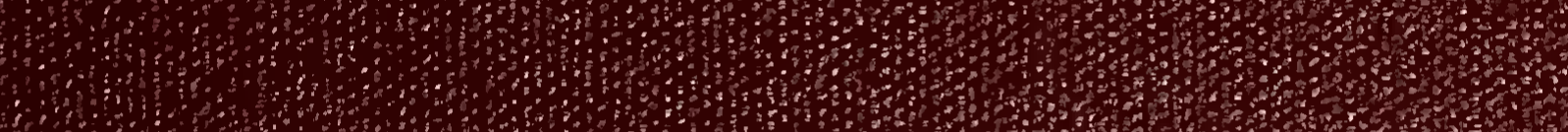

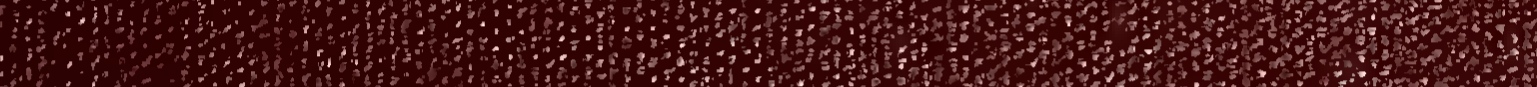

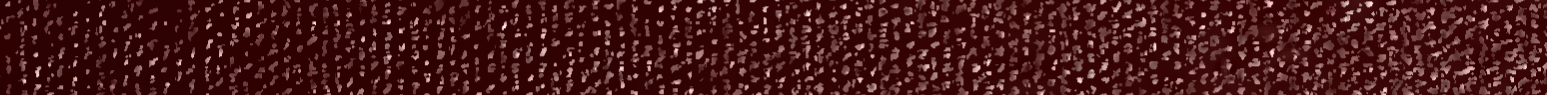

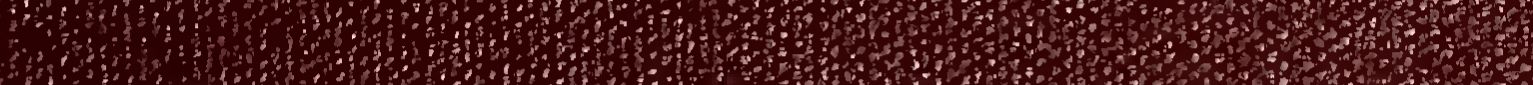

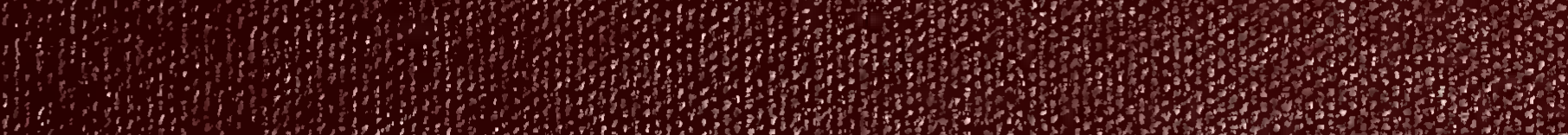

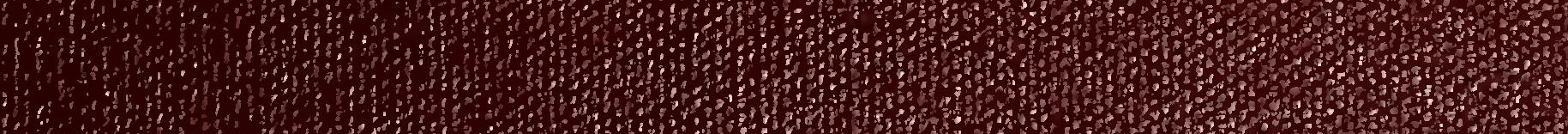
m,

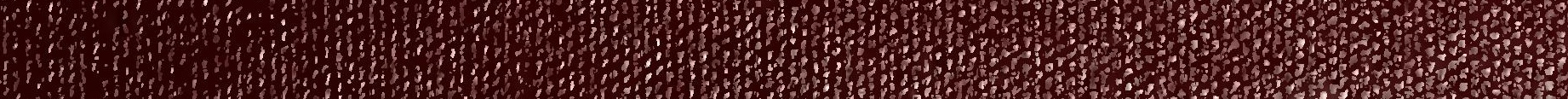
. 1. 